\title{
KNOWLEDGE AND PRACTICES OF STOMA CARE AMONG PATIENTS AT TERTIARY CARE HOSPITAL LAHORE PAKISTAN
}

\author{
Hafiza Neelam, Reg \# PBSNO2183005 \\ Lahore School of Nursing \\ The University of Lahore \\ Lahore, Pakistan \\ hafizaneelam055@gmail.com \\ Muhammad Hussain, Assistant Professor \\ Lahore School of Nursing \\ The University of Lahore \\ Lahore, Pakistan \\ mhussainsial@gmail.com \\ Muhammad Afzal, associate professor \\ Lahore School of Nursing \\ The University of Lahore \\ Lahore, Pakistan \\ mafzalaku@gmail.com \\ Prof. Dr. Syed Amir Gilani \\ Lahore School of Nursing \\ The University of Lahore \\ Lahore, Pakistan \\ profgilani@gmail.com
}

\begin{abstract}
Introduction: Stoma and ostomy are Greek terms meaning mouth or opening done to treat several benign and malignant intestinal conditions, due to a change in bowel habits, anatomically modified by surgical creation of an opening in the abdominal wall involving parts of the gastrointestinal tract. Formation of colostomy is sometimes necessary and at other times mandatory. The colostomy patients wear a disposable pouch to collect the stool. A colostomy may be temporary or permanent, depending on the medical reason for the surgery Methodology: quantitative observational descriptive study design was used to assess the knowledge and practices of stoma care among patients at tertiary care hospital, data was collected through the standardized questionnaire regarding stoma care. The questionnaire consists of 28 items. Results: The findings of this study revealed that there are poor knowledge and practices of patients regarding stoma care. Conclusion: In this study, patients with moderately levels of knowledge about stoma care and those who cannot manage all aspects of care independently were not more psychosocially adjusted to their stomas than persons with high knowledge and not more dependence on others for care. The results of this and other studies suggest providing knowledge and emphasizing/teaching selfcare before hospital discharge may optimize quality of life for persons with a colostomy.
\end{abstract}

Key words: Stoma, Practice, Care, Patient.

DOI: $10.7176 / \mathrm{JHMN} / 74-10$

Publication date:May $31^{\text {st }} 2020$

\section{CHAPTER - I}

\section{INTRODUCTION}

Background: Stoma and ostomy are Greek terms meaning mouth or opening done to treat several benign and malignant intestinal conditions, due to a change in bowel habits, anatomically modified by surgical creation of an opening in the abdominal wall involving parts of the gastrointestinal tract. Formation of colostomy is sometimes necessary and at other times mandatory. The colostomy patients wear a disposable pouch to collect the stool. A colostomy may be temporary or permanent, depending on the medical reason for the surgery (Wilson, 2019). 
Intestinal ostomy is a surgical procedure that is done to treat several benign and malignant intestinal conditions. Colorectal malignancies, inflammatory bowel disease, polyposis syndromes and trauma are few conditions in which stomas are used. The two most leading causes are colorectal malignancies and inflammatory bowel disease (Dincer \& Çıtlak, 2019).

Furthermore the incidence of colorectal malignancies are on the rise worldwide which is also now seen among the Asian population. The significant increase in morbidity and mortality has made colorectal cancer a major public health concern. Increase in the incidence of colorectal malignancies has significantly contributed to the increase in ostomy creation (Golicki, Styczen, \& Szczepkowski, 2013).

Due to increasing incidence of colorectal cancer and urinary cancer, stoma surgery rate is also increasing. There are more than 1 million patients with a permanent colostomy and the number is increasing by the rate of 100000 per year. (Pandey, Baral, \& Dhungana, 2015).

The adverse impacts on stoma patients are physical, psychological and social. The physical problems of ostomates included leakage, skin problems, ballooning and odor. (Bajracharya, 2010) The most common physical problems with the stoma include leaking, peristomal skin problems, and the need for adaptation of stoma appliances and the need for adaptation of clothing to the presence and site of the stoma which has a significant impact on the patient's daily life (Shaffy, Kaur, Das, \& Gupta, 2012).

Depending on stoma surgery, not only excretion form of individuals but also individuality, self-respect, sense of independence, sexual life, nutritional status, social life, working life, dressing cases, self-care learning and functional abilities are affected (Lim, Chan, \& He, 2015). Gas and odor, fecal leakage, skin problems, fatigue, loss of appetite, indigestion, nausea, diarrhea, constipation, hernia, pain (Reese et al., 2014) stool leakage, bad smell, the independence of the reduction due to depression, anxiety (Danielsen \& Rosenberg, 2014) Peristomal skin irritation and infections, social isolation, reduction in the frequency of social activity, problems in sexual life, business life problems, travel difficulties and body image problems are most common experienced stoma problems by individuals (Werth, Schutte, \& Stommel, 2014).

These psycho-social conditions, anxiety, depression, leisure activities, determining the business case, professional roles and functional status of the characteristics of individuals are the basic contents of quality of life and it's indicated in studies that stoma surgery affect the quality of life Accordingly, conditions that affect the quality of life is closely related supplying self-care needs (Tao, Songwathana, Isaramalai, \& Wang, 2014). It is generally understood that a stoma has a negative impact on people's quality of life. This negative impact can affect self-care practices that may result in disturbed life (Costa, Alves, Eufrásio, Salomé, \& Ferreira, 2014).

Self-efficacy is described as human being's beliefs about their talents to provide exact degrees of overall performance that have an impact on activities affecting their lives. The beliefs decide how people feel, assume, inspire themselves and behave, delivered to manufacturing diverse effects via cognitive, motivation, affective and processes of choosing (Artino, 2012).

Stoma care self-efficacy is defined as the conviction by patients that they can successfully manage their stoma to minimize adverse outcomes. Stoma care self-efficacy has been positively related to ostomy adjustment (Neuman et al., 2011).

Self-care is defined as performing necessary activities that are basic needs of the individual and self-care ability is defined as the ability to perform these activities. (Richard \& Shea, 2011).

By the way self-care is an important part for the adaptation of patients with stomas and healthy behaviors after surgery Clients with a new stoma must master multiple psychomotor skills to remove their pouch, clean the stoma and periosteal skin and empty and dispose of effluent from the pouch. Stoma care self-efficacy has been positively related to ostomy adjustment (Bulkley et al., 2018).

Patient with higher levels of knowledge about stoma care and those who can manage all aspects of care independently were more psychosocially adjusted and had higher self-esteem level to their stomas than persons with less knowledge and more dependence on others for care. This may be related to when patients be independent in performing stoma care well and able to deal with their conditions they feel best control over themselves and their view and value about themselves changed positively this increase patients' level of self-esteem. (El Sayed, Elhameed, \& Hassanen).

Unsatisfactory level of knowledge and self-care practice among adolescents and adults patients with permanent stoma affect the quality of life and self-efficacy among this kind of patients. To provide a holistic care for such 
patients, assessment of all aspects related to stoma are important to deliver individualized and appropriate care that improve QOL and enhance self-efficacy among patients with colostomy (Mohamed, Salem, \& Mohamed, 2017).

Self-care management preparation as the training the people with chronic health conditions need to be able to deal with taking medication and maintaining therapeutic regimes, maintaining everyday life such as employment and family, and dealing with the future, including changing life plans and the frustration, anger, and depression that accompanies a chronic condition. A stoma is not generally labeled as a chronic condition, but living with a stoma requires that the client learn many of the same self-management skills. However, many health-care providers must give the stoma-related knowledge and skills to provide education and clinical support to enable clients to make informed decisions, achieve their goals and overcome barriers to effective self-management (Culha, Kosgeroglu, \& Bolluk, 2016).

Self-management education includes traditional patient education but also involves helping patients to learn techniques of problem-solving. Self-Management Support Programs aim to Change Patient Behavior by increasing the patients' self-efficacy and knowledge. Improved behavior is expected to lead to better disease control which should, in turn, lead to better patient outcomes and reduced utilization of health care services, particularly preventable emergency room visits and hospitalizations, and ultimately to reduced costs (Ran et al., 2016).

Problem statement: Stoma has a negative impact on the psychosocial aspects of colostomy patients as presence of anxiety, depression and lack of self-esteem. National Digestive Diseases association (24), confirmed that patients with colostomy are at increased risk of depression and social isolation as at least $25 \%$ of patients develop clinically significant depression following colostomy (El Sayed et al.).

Adaptation to such big change in life is important as these patients needs to experience new behavior for selfmanagement and self-care. Successful adaptation of new behavior requires knowledge and skills and certain levels of self-efficacy to enhance quality of life (Culha et al., 2016)

To target education to patients with permanent stoma, it is one of the basic step to assess their educational needs. Therefore, there is need to assess the level of knowledge about stoma and stoma self-care practice among patients in Pakistan.

Aim of study: Aim of study is to assess knowledge and self-care practices among patients with the intestinal ostomy.

\section{Research questions:}

1. What is the patient's level of knowledge regarding self-stoma care?

2. What are the patient's practices for the care the intestinal stoma?

\section{Operational definitions:}

Knowledge: in this study the knowledge will be the right and accurate information of patients regarding ostomy care.

Practice: practice will be correct techniques and methods of caring ostomy opening.

Self-care: in present study self-care will be the care and protection of ostomy opening by patient own.

\section{Conceptual definitions:}

Knowledge: awareness or familiarity gained by experience of a fact or situation.

Practice: the actual application or use of an idea, belief, or method, as opposed to theories relating to it.

Self-care: the practice of taking an active role in protecting one's own well-being and happiness, in particular during periods of stress.

\section{CHAPTER - II}

\section{LITERATURE REVIEW}

Colorectal cancer (CRC) is considering as a major global health problem because of its high incidence and mortality rates, in the USA, CRC is the third commonest type of malignancy and the fourth leading cause of cancer- 
related deaths internationally, accounting for approximately one million and forty thousand new cases and about seven hundreds deaths worldwide(Arnold et al., 2017).

The increasing incidence of colorectal cancer and urinary cancer, stoma surgery rate is also increasing, teaching on stoma care and stoma skills given by enterostomal therapist during post-operative and discharge period enable clients to increase self-efficacy in ostomy management (Pontieri-Lewis, 2018).

United Ostomy Association 2015 stated that over 750,000 Americans currently have an ostomy, however; about $36 \%$ of the surgeries performed are colostomies. While, in Hong Kong, There are approximately 15,000 patients with a stoma(Nichols \& Inglese, 2018).

Furthermore, in Netherlands 2017, there are about 32,000persons with permanent stoma, other report estimates that 650,000 people in Egypt currently have a stoma and about 3000 new surgeries are performed each year with colostomy approximately 832 patients (Sheikh, Joel, Johnson, \& Vimalachandran, 2016).

A variety of gastrointestinal/genitourinary etiologies may necessitate the creation of a fecal or urinary diversion, hese may include colostomy for colon-rectal cancer, diverticular disease, inflammatory bowel disease, intestinal obstruction, gastrointestinal trauma, and gynecological cancers (Pandey et al., 2015).

According to hospital based cancer registry in Nepal 2007, Ca Urinary bladder is 6th common in male >64yrs whereas Ca rectum is 6th common in female 15-34 yrs and male 1534 years (Pradhananga, Baral, \& Shrestha, 2014).

A study shows that there are more than 1 million patients with a permanent colostomy in China, and the number is increasing by the rate of 100000 per year Clients with a new ostomy must master multiple psychomotor skills to remove their pouch, clean the ostomy and peristomal skin and empty and dispose of effluent from the pouch (Cheng, Xu, Dai, \& Yang, 2015).

The mean knowledge score of illiterate was 3.31 and that of literate was 3.87 , which is slightly different but it is statistically insignificant since $\mathrm{p}$ value is 0.314 . The mean knowledge score of ostomates receiving and not receiving pre-operative teaching were 4.40 and 3.48 respectively (Pandey et al., 2015).

The difference is statistically significant since $\mathrm{p}$ value is 0.03 . The mean knowledge score of ostomates receiving training was 5.00 and that of not receiving training was 3.25 , which is significantly significant as $p$ value is 0.00 (Pandey et al., 2015).

An Interventional study was done among Permanent Colostomy in china to assess knowledge about colostomy care, colostomy products, prevention and treatment of complications, types and storage of colostomy bags, and colostomy irrigation. Higher scores represent higher level of knowledge. The result showed pre-course mean was knowledge 51.89. Similarly self-care efficacy was 71.56 (Cheng, Xu, Dai, \& Yang, 2012).

As regards to the studied subjects' knowledge score throughout the study phases, the results of the a study revealed that the majority of patients had poor knowledge of colostomy care (El Sayed, Elhameed, \& Hassanen, 2017).

A study conducted in ejypt elaborated that, the total scores of studied subject's practice throughout the study phases was not good, the results of present study revealed that, there were poor practices of colostomy care (Mohamed et al., 2017).

In the daily care practices of ostomates, $84 \%$ ostomates perform hand washing before cleaning stoma and changing stoma bag whereas all of them perform hand washing after the procedure. Likewise, $47.9 \%$ of ostomates empty the pouch when it is half filled, $43.6 \%$ of ostomates empty pouch whenever pouch is $1 / 3$ rd filled, $4.3 \%$ empty it in $<1 / 3$ rd filled. Remaining $1.1 \%$ empty the pouch whenever they feel it uncomfortable. $75.5 \%$ of ostomates clean stoma from periphery to centre and remaining clean from centre to periphery (Pandey et al., 2015).

$23 \%$ of ostomates had adequate knowledge on ostomy care, $58 \%$ of ostomates had moderate knowledge and $18 \%$ had inadequate Knowledge. On attitude, 65\% shown undesirable attitude and 35\% shown desirable attitude towards ostomy care. With regarding to practice, $52 \%$ of respondent shown adequate practice and $45 \%$ inadequate practice (SHANMUGAM \& ANANDHI, 2016).

As reported in a study, about two thirds of the adolescents reported fair knowledge and one third reported poor knowledge regarding definition, causes, types, complication and risks of stoma. On the other hands, $48 \%$ of the adults reported fair knowledge and $41 \%$ reported poor knowledge of stoma definition, causes, types, complication and risks of stoma, more than half of the adolescents reported fair knowledge and more than one third reported 
good knowledge regarding stoma pouch, appliance for stoma, criteria of changing pouch of stoma portrayed (Mohamed et al., 2017).

Fifty-eight percent of the adults reported good knowledge and $27 \%$ reported fair knowledge regarding this item. $64 \%$ of the adolescents and $50 \%$ of adults reported fair knowledge of diet, fluids and activity. In this regard, $18 \%$ of adolescents and $41 \%$ of adults reported good knowledge. Knowledge of self-care practice was presented as fair among $50 \%$ of the adolescents and $43 \%$ among adults (Culha et al., 2016).

Preparation of pouch: A study conducted in Egypt indicated that $93.3 \%$ of respondents were performing pouch preparation inappropriately and $6.7 \%$ were performing only in acceptable way. Another study showed that patient have no appropriate technique for colostomy care (Mohamed et al., 2017).

Removal of old pouch: another study elaborated that the clients were handling colostomy pouches in totally nonprofessional way about $90 \%$ of respondents did not know the proper techniques to deal with pouches during colostomy care (Scharlach, Barrie Robinson, Dal Santo, Guinta, \& Kelly Mills-Dick, 2014).

Clean stoma and skin around stoma: according to a study results showed that about $94 \%$ of study participants was totally unknowing regarding care of colostomy, $4 \%$ have fare knowledge of colostomy care and $2 \%$ were total blank according to situation (Stoker, 2016).

Apply the pouch: another study conducted in Ethopia showed that about $73 \%$ patient have no proper knowledge and techniques of applying of pouches during care of colostomy, in this reference only $7 \%$ patient have proper techniques to apply pouches during colostomy care (Geleta, 2017).

Empty and clean the pouch: according to Lim only 30\% patient knows about emptying and cleaning of colostomy pouches and $70 \%$ patient did not know about the convenient method of colostomy care (Lim et al., 2015).

Stoma irrigation: stoma irrigation is a way to manage bowel movements by emptying the colon at a scheduled time but $80 \%$ patient not doing stoma irrigation properly only $6.7 \%$ patients doing in good way and $13.3 \%$ doing in only acceptable way (Pattanaik, 2018).

The objective of the study is to;

\section{OBJECTIVES}

- Assess knowledge of patients regarding self-stoma care.

- Evaluate self-care practices of patients with the intestinal ostomy.

\section{SIGNIFICANCE OF STUDY}

It will help to assess knowledge of patients regarding self-stoma care. It will refine the previous knowledge and practice regarding self-stoma care. This study will help to assess the need of educational programs for patients regarding ileostomy self-care.

\section{CHAPTER - III \\ MATERIAL AND METHODS}

Study Design:

Observational study Design

\section{Setting:}

The current study was conducted in tertiary care hospital of Lahore

\section{Duration of the study:}

The study was taking 4 months (February 28.2020 to May 3, 2020).

\section{Target Population:}

All the patients with the intestinal ostomy.

\section{Sample Size and Sampling method}


Slovin's sampling formula will be used to find the sample size of the study population.

Where, $n=$ sample size, $\mathrm{N}=$ number of total populations, $\mathrm{e}=$ Error margin of 0.05 when confidence interval is $95 \%$.

If the total population is 240 , so according to formula:

$$
\begin{aligned}
& \mathrm{n}=\mathrm{N} / 1+(\mathrm{N})(\mathrm{E})^{2} \mathrm{n}=200 / 1+(240)(0.05)^{2} \\
& \mathrm{n}=240 / 1+(240)(0.0025) \\
& \mathrm{n}=240 / 1+0.6 \\
& \mathrm{n}=240 / 1.6 \\
& \mathrm{n}=150
\end{aligned}
$$

So, the study sample will be the 150 .

\section{Sampling Technique:}

Convenient sampling technique will be used.

\section{Inclusion criteria: -}

- Able to communicate and willing to participate in the study

- Have normal cognitive function.

\section{Exclusion Criteria: -}

- Have severe organ failure (heart, lung or Liver) or terminal illness (Life expectancy 6 months when known) that severe enough to limit patient autonomy.

- With previous psychiatric history or illness.

- Any patient attends an educational program about stoma care before.

Data Analysis: Data was analyzed on SPSS (version 22).

- Data analyzed in percentage and frequency form by using bar charts.

\section{Data collection instruments}

Data was collected by using well adopted questionaire recently used in 2015 by Radha Acharya Pandey, Sandhya Baral, Govinda Dhungana. It consists of four sections as following;

Section A: in which includes demographic data such as Age, Gender, Duration of postoperative hospitalization, Education level, Duration of living with stoma etc.

Section B: In which include 6 Item to assess knowledge regarding complication of stoma and normal stoma.

Section C: in which include 9 items to assess the daily care practices and practices regarding physical problem and management.

Section D: it consists 13 items for assessment of self-care efficacy

\section{Ethical considerations}

In the study, ethical principles and values taken into consideration and participants' ethical rights were fully respected.

1. The respondents of the study were asked to sign consent forms before responding to the questionnaire. And respondents informed about withdrawal from study if they are uncomfortable without any penalty.

2. Respondents assured that their information would be kept confidential, and no assess would be allowed to their names, designation and addresses.

3. The data collected were not fabricated. There is no addition of data or characteristics in collected data for the required results of the study

4. Participant of the research were not force to participate by giving them any rewards, incentives or bait. 


\section{CHAPTER - IV \\ RESULTS}

This study is conducted at Jinnah hospital to assess the knowledge and practices of stoma care among patients. The result of this study distributed into two sections, first section is statistics of demographic factors of patients admitted in hospital acquiring care regarding stoma and second is frequency and statistics of items regarding stoma care among patients and assessment the patients practices accordingly.

Section A: Table 1 shows that the frequency of demographics includes age, Education level, Duration of living with stoma, Duration of postoperative hospitalization, Type of stoma, Training on stoma care, and Pre-operative teaching of the 150 participants and the results revealed that the age of participants was found minimum 21 to highest 60, participant's age group 21-30 years frequency was 18 (12\%), moderately 48 (32\%) participants were belong to age group 31-40 years and $55(36.7 \%)$ were fall in age group 41 - 50 years and majority $29(19.3 \%)$ were 51-60-year-old.

Only $10(6.7 \%)$ participants have Higher education (above 12$)$ and majority $53(35,3 \%)$ were belong to primary (class 1-8), 36 (24\%) were educated as Lower secondary (class 9-10), 35 (23.3\%) were Illiterate and $16(10.7 \%)$ were educated as higher secondary (class 11-12). Majority 79 (52.7\%) of participants' living with stoma $\leq 12$ months and $71(47.3 \%)$ living with stoma for $\geq 12$ months. Duration of postoperative hospitalization of the participants was found as $93(62 \%)$ were stayed in hospital for $\leq 15$ days and $57(38 \%)$ were stay for $\geq 15$ day. Assessment regarding Type of stoma and results revealed that majority 68 (45.3\%) have found with Ileostomy, 56 $(37.3 \%)$ have found with Colostomy and $26(17.3 \%)$ found with Urostomy. $89(52.7 \%)$ have training and 61 $(47.3 \%)$ have not Training on stoma care. 72 (48\%) found as having Pre-operative teaching and majority 78 (52\%) having Pre-operative teaching regarding stoma care.

\begin{tabular}{|c|c|c|c|}
\hline \multicolumn{4}{|c|}{ Demographics } \\
\hline & Demographic Variable & Frequency & Valid Percent \\
\hline Age: & $\begin{array}{l}21-30 \text { years } \\
31-40 \text { years } \\
41-50 \text { years } \\
51-60 \text { years } \\
\text { Total }\end{array}$ & $\begin{array}{c}18 \\
48 \\
55 \\
29 \\
\mathbf{1 5 0}\end{array}$ & $\begin{array}{c}12 \% \\
32 \% \\
36.7 \% \\
19.3 \% \\
\mathbf{1 0 0 . 0} \%\end{array}$ \\
\hline Education level: & $\begin{array}{l}\text { Illiterate } \\
\text { Primary (class 1-8) } \\
\text { Lower secondary (class 9-10) } \\
\text { Higher secondary (class 11-12) } \\
\text { Higher education (above 12) } \\
\text { Total }\end{array}$ & $\begin{array}{c}35 \\
53 \\
36 \\
16 \\
10 \\
\mathbf{1 5 1}\end{array}$ & $\begin{array}{c}23.3 \% \\
35.3 \% \\
24.0 \% \\
10.7 \% \\
6.7 \% \\
\mathbf{1 0 0 . 0} \%\end{array}$ \\
\hline $\begin{array}{l}\text { Duration of living } \\
\text { with stoma: }\end{array}$ & $\begin{array}{l}\leq 12 \text { months } \\
\geq 12 \text { months } \\
\text { Total }\end{array}$ & $\begin{array}{c}79 \\
71 \\
\mathbf{1 5 1}\end{array}$ & $\begin{array}{c}52.7 \% \\
47.3 \% \\
\mathbf{1 0 0 . 0} \% \\
\end{array}$ \\
\hline $\begin{array}{l}\text { Duration of } \\
\text { postoperative } \\
\text { hospitalization }\end{array}$ & $\begin{array}{l}\leq 15 \text { days } \\
\geq 15 \text { day } \\
\text { Total }\end{array}$ & $\begin{array}{c}93 \\
57 \\
150\end{array}$ & $\begin{array}{c}62 \% \\
38 \% \\
\mathbf{1 0 0 . 0} \%\end{array}$ \\
\hline Type of stoma & $\begin{array}{l}\text { Colostomy } \\
\text { Ileostomy } \\
\text { Urostomy } \\
\text { Total }\end{array}$ & $\begin{array}{c}56 \\
68 \\
26 \\
\mathbf{1 5 0}\end{array}$ & $\begin{array}{l}37.3 \% \\
45.3 \% \\
17.3 \% \\
\mathbf{1 0 0} \%\end{array}$ \\
\hline $\begin{array}{l}\text { Training on stoma } \\
\text { care }\end{array}$ & $\begin{array}{l}\text { Yes } \\
\text { No } \\
\text { Total }\end{array}$ & $\begin{array}{c}89 \\
61 \\
\mathbf{1 5 0} \\
\end{array}$ & $\begin{array}{l}52.7 \% \\
47.3 \% \\
\mathbf{1 0 0} \%\end{array}$ \\
\hline $\begin{array}{l}\text { Pre-operative } \\
\text { teaching }\end{array}$ & $\begin{array}{l}\text { Yes } \\
\text { No } \\
\text { Total }\end{array}$ & $\begin{array}{c}72 \\
78 \\
\mathbf{1 5 0}\end{array}$ & $\begin{array}{c}48 \% \\
52 \% \\
100 \%\end{array}$ \\
\hline
\end{tabular}

Table 1

Table 2 shows the mean, median, mode and standard deviation of demographic variable the highest mean 2.63 for age, then 2.42 for Duration of living with stoma and 1.80 for Duration of postoperative hospitalization, 1.47 and 1.41 for Type of stoma and Training on stoma care respectively and Pre-operative teaching was 1.52 . The Std. Deviation is $(.930, .487,1.154, .714, .501, .493, .501)$ were respectively for, age, Education level, Duration of 
living with stoma, Duration of postoperative hospitalization, Type of stoma, Training on stoma care, and Preoperative teaching, Highest median value is 3.00 and highest mode value is 3 .

Demographics Statistics

\begin{tabular}{|l|c|c|c|c|c|}
\hline \multicolumn{1}{|c|}{ Variable } & N & Mean & Median & Mode & $\begin{array}{c}\text { Std. } \\
\text { Deviation }\end{array}$ \\
\hline Age: & 150 & 2.63 & 3.00 & 3 & .930 \\
\hline Education level: & 150 & 1.38 & 1.00 & 1 & .487 \\
\hline Duration of living with stoma: & 150 & 2.42 & 2.00 & 2 & 1.154 \\
\hline $\begin{array}{l}\text { Duration of postoperative } \\
\text { hospitalization }\end{array}$ & 150 & 1.80 & 2.00 & 2 & .714 \\
\hline Type of stoma & 150 & 1.47 & 1.00 & 1 & .501 \\
\hline Training on stoma care & 150 & 1.41 & 1.00 & 1 & .493 \\
\hline Pre-operative teaching & 150 & 1.52 & 2.00 & 2 & .501 \\
\hline
\end{tabular}

Table 2

Figure 1 shows that the results regarding age of participants was found minimum 21 to highest 60 , participant's age group 21-30 years frequency was 18 (12\%), moderately $48(32 \%)$ participants were belong to age group 31 40 years and $55(36.7 \%)$ were fall in age group 41- 50 years and majority 29 (19.3\%) were 51-60-year-old.

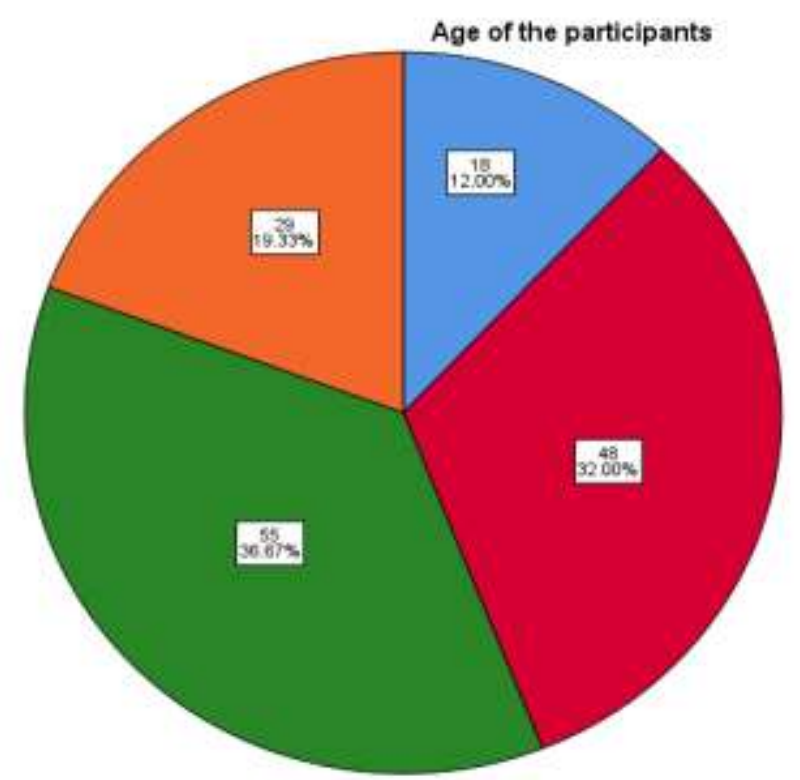

Figure 1

Figure 2 shows that the duration of postoperative hospitalization of the participants was found as $93(62 \%)$ were stayed in hospital for $\leq 15$ days and $57(38 \%)$ were stay for $\geq 15$ day. 


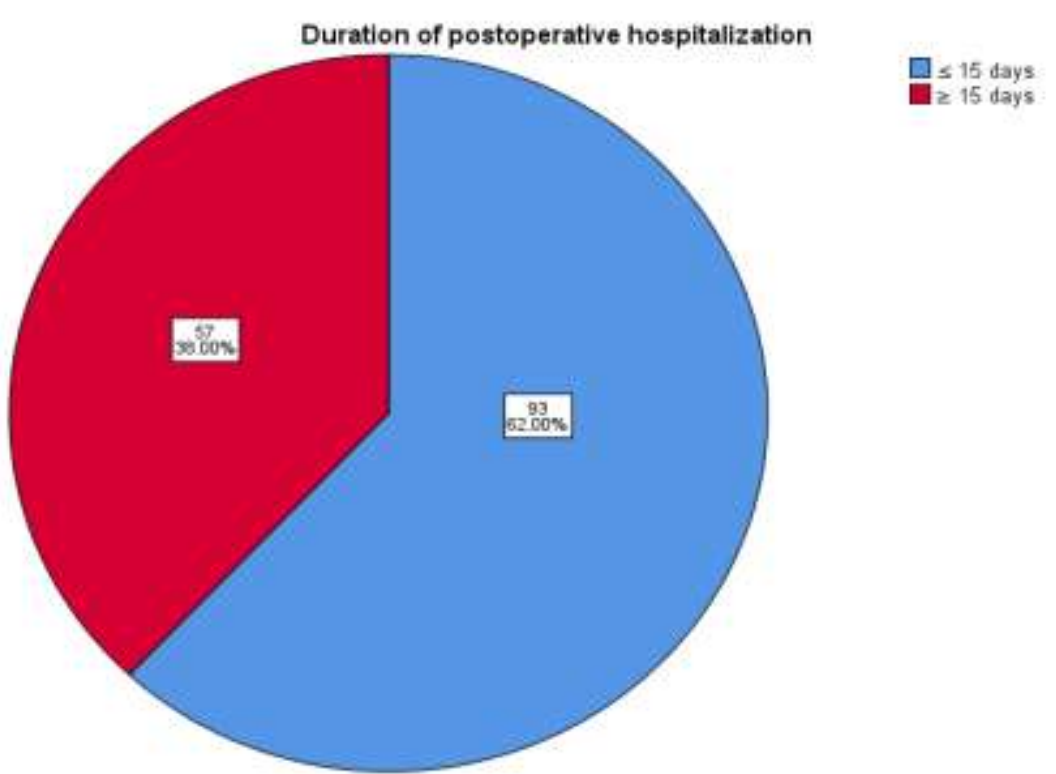

Figure 2

Figure 3 shows that the only $10(6.7 \%)$ participants have Higher education (above 12$)$ and majority $53(35,3 \%)$ were belong to primary (class 1-8), 36 (24\%) were educated as Lower secondary (class 9-10), 35 (23.3\%) were Illiterate and $16(10.7 \%)$ were educated as higher secondary (class 11-12).

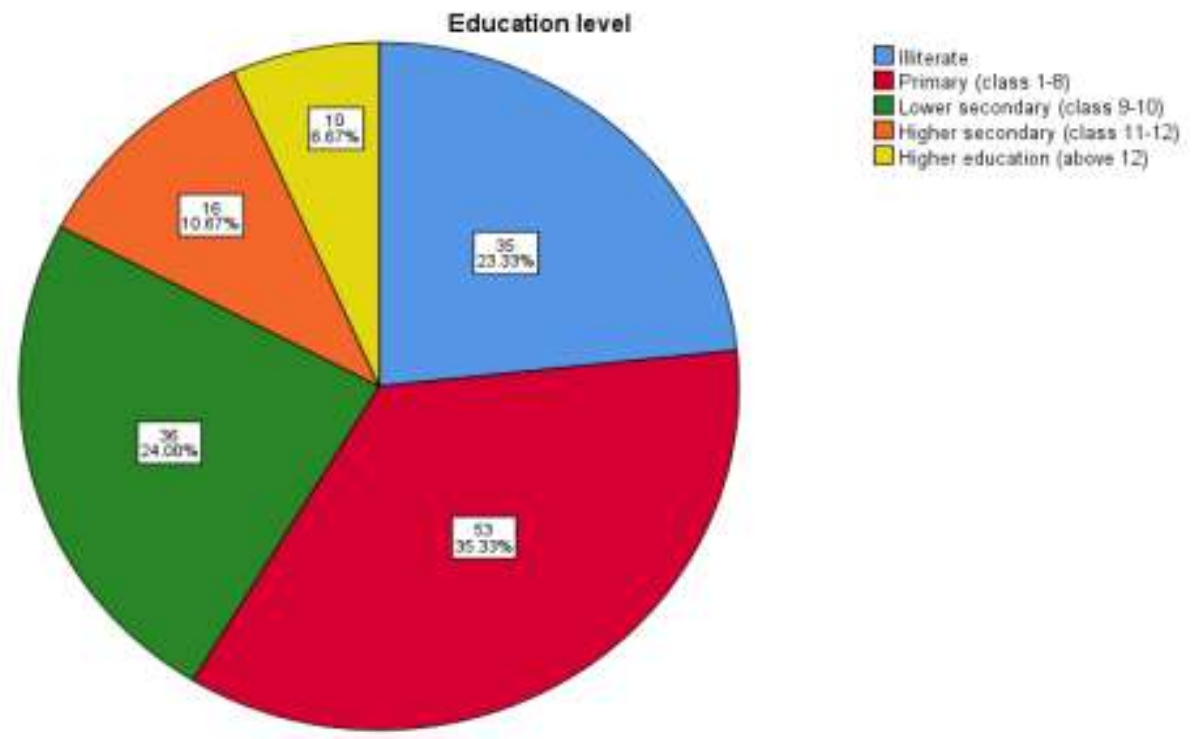

Figure 3

Figure 4 shows that the assessment results regarding Type of stoma and results revealed that majority 68 (45.3\%) have found with Ileostomy, $56(37.3 \%)$ have found with Colostomy and $26(17.3 \%)$ found with Urostomy. 


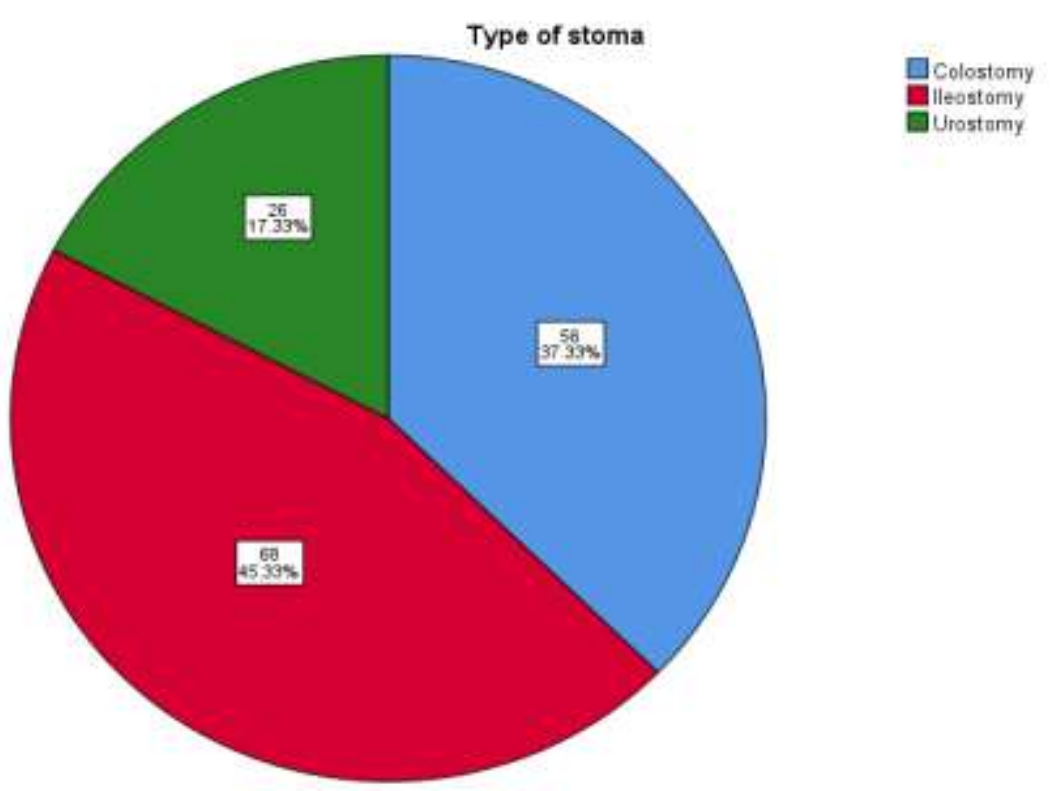

Figure 4

Figure 5 shows that the majority 79 (52.7\%) of participants' living with stoma $\leq 12$ months and $71(47.3 \%)$ living with stoma for $\geq 12$ months.

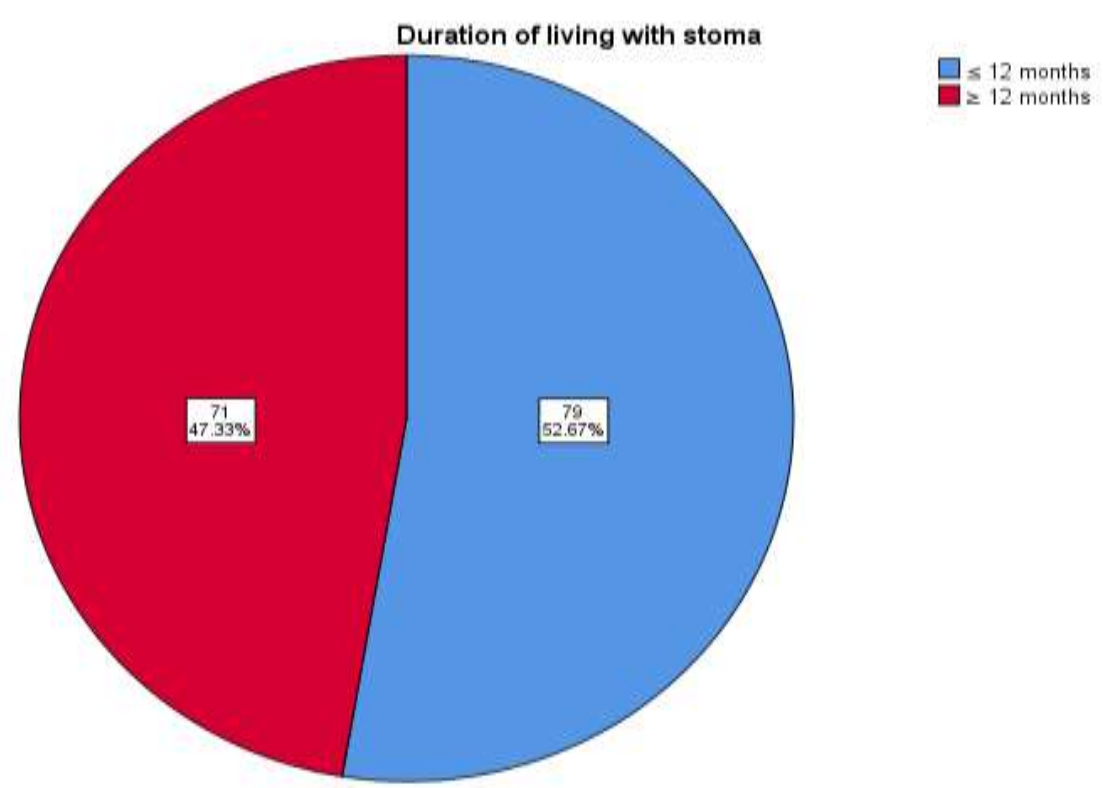

Figure 5

Figure 6 shows that the $89(52.7 \%)$ have training and $61(47.3 \%)$ have not Training on stoma care. 


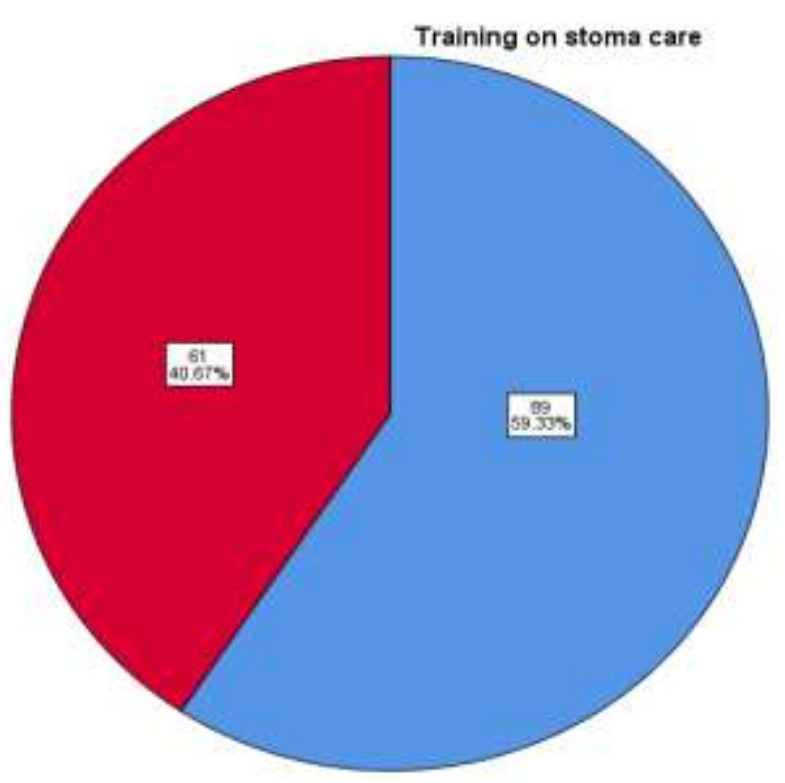

Figure 6

Figure 7 shows that the $72(48 \%)$ found as having Pre-operative teaching and majority 78 (52\%) having Preoperative teaching regarding stoma care.

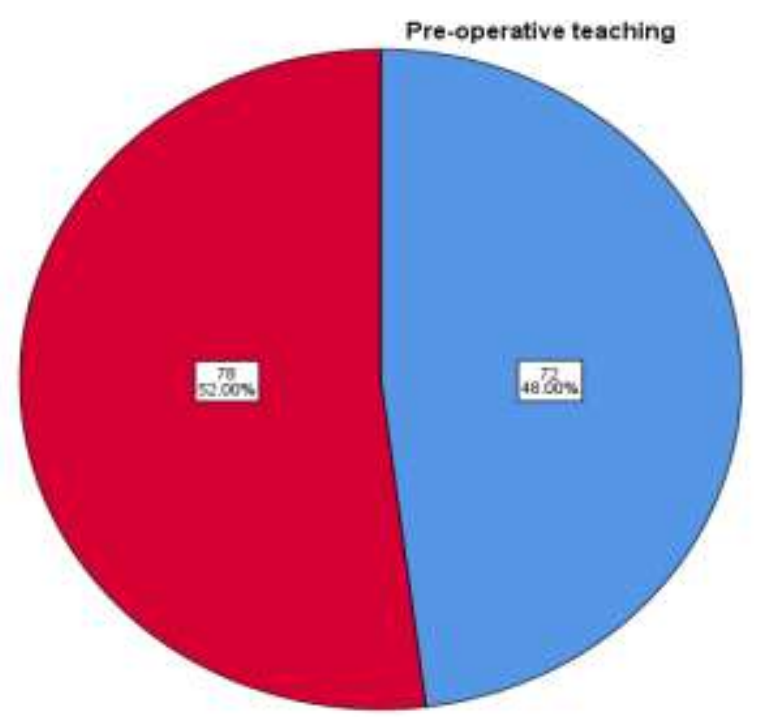

Figure 7

Section B: consist of items to assess the participants regarding stoma care knowledge and practices consisting 28 items.

Table 3 shows the frequency percentage of 3 items of questionnaire regarding stoma care for assessing the knowledge accordingly and results revealed that nearly $50 \%$ participants have good knowledge regarding stoma care. The participants response regarding item one which was "Black colored stoma is normal" 60 (40\%) response as yes, which is correct, $59(39.3 \%)$ go with no and only $31(20.7 \%)$ response as not know the color of stoma. Item two is "stoma protruded $>2$ inch is normal" and majority $60(40 \%)$ response correctly as yes, $52(34.7 \%)$ response wrongly as no and $38(25.3 \%)$ were not know the stoma protruded $>2$ inch is normal. The participants response regarding three which is "Continued bleeding from inside stoma for $>10 \mathrm{~min}$ is normal" as majority 88 (58.7\%) were go with yes, $54(36 \%)$ response as yes and only $8(5.3 \%)$ did not know about it.

\begin{tabular}{|c|c|c|c|c|c|c|}
\hline \multicolumn{7}{|c|}{ Knowledge regarding Complication of Stoma } \\
\hline Items & $\begin{array}{c}\text { Yes } \\
\text { F }\end{array}$ & F \% & $\begin{array}{c}\text { No } \\
F\end{array}$ & F \% & $\begin{array}{c}\text { Not know } \\
\text { F }\end{array}$ & F \% \\
\hline Black colored stoma is normal & 60 & $40 \%$ & 59 & $39.3 \%$ & 31 & $20.7 \%$ \\
\hline
\end{tabular}




\begin{tabular}{|l|c|c|c|c|c|c|}
\hline Stoma protruded >2 inch is normal & 60 & $40 \%$ & 52 & $34.7 \%$ & 38 & $25.3 \%$ \\
\hline Continued bleeding from inside stoma...... & 88 & $58.7 \%$ & 54 & $36 \%$ & 8 & $5.3 \%$ \\
\hline
\end{tabular}

Table 3

Table 4 show that mean, median, mode and standard deviation of three items of questionnaire to assess the participants knowledge regarding stoma care and the highest mean 1.85 for Stoma protruded $>2$ inch is normal, then 1.81 for Stoma protruded $>2$ inch is normal and lowest 1.47 for Continued bleeding from inside stoma for $>10 \mathrm{~min}$ is normal. The Std. Deviation is $(.757, .798$ and .598 were respectively for item one, two and three. Highest median value is 2.00 and highest mode value is 1 .

\section{Knowledge statistics regarding Complication of Stoma}

\begin{tabular}{|l|c|c|c|c|c|}
\hline \multicolumn{1}{|c|}{ Items } & $\mathbf{N}$ & Mean & Median & Mode & $\begin{array}{c}\text { Std. } \\
\text { Deviation }\end{array}$ \\
\hline Black colored stoma is normal & 150 & 1.81 & 2.00 & 1 & .757 \\
\hline Stoma protruded >2 inch is normal & 150 & 1.85 & 2.00 & 1 & .798 \\
\hline Continued bleeding from inside stoma..... & 150 & 1.47 & 1.00 & 1 & .598 \\
\hline
\end{tabular}

Table 4

Table 5 show that the participants response regarding the knowledge of stoma care and results revealed regarding the item four which is "Color of normal stoma" and participants response as $38(25.3 \%)$ go with red, majority 63 (42\%) go with pale, 39 (26\%) response as black and only $10(6.7 \%)$ response as not know about the color of normal stoma. Item five is "Appearance of normal stoma" and participants response as $25(16.7 \%)$ go with shiny and moist, majority $55(36.7 \%)$ response as has nodules, $48(32 \%)$ response as has cuts and torn and only 22 did not know about the appearance of normal stoma. Item six is "Normal peristomal skin condition" and participants response as $25(16.7 \%)$ go with Similar to other skin, majority $49(32.7 \%)$ response as red, $48(32 \%)$ response as painful to touch and only $22(18.7 \%)$ did not know about the normal peristomal skin condition.

Knowledge regarding Normal Stoma

\begin{tabular}{|l|c|c|c|c|c|c|c|c|}
\hline \multicolumn{1}{|c|}{ Items } & $\mathbf{1 ~ F}$ & $\mathbf{F \%}$ & $\mathbf{2 ~ F}$ & $\mathbf{F \%}$ & $\mathbf{3 ~ F}$ & $\mathbf{F \%}$ & $\mathbf{4 ~ F}$ & $\mathbf{F \%}$ \\
\hline Color of normal stoma & 38 & $25.3 \%$ & 63 & $42 \%$ & 39 & $26 \%$ & 10 & $6.7 \%$ \\
\hline Appearance of normal stoma & 25 & 16.7 & 55 & $36.7 \%$ & 48 & $32 \%$ & 22 & $18.7 \%$ \\
\hline Normal peristomal skin condition & 25 & $16.7 \%$ & 49 & $32.7 \%$ & 48 & $32 \%$ & 22 & $18.7 \%$ \\
\hline
\end{tabular}

Red=1, Pale=2, Black=3, Don't know=4

Shiny and moist $=1$, Has nodules $=2$, Has cuts and torn $=3$

Similar to other skin=1, Red=2, Painful to touch=3, Frequency $=\mathrm{F}$

Table 5

Table 6 show that mean, median, mode and standard deviation of three items of questionnaire to assess the participants knowledge regarding stoma care and the highest mean 2.53 for Normal peristomal skin condition, then 2.45 for Appearance of normal stoma and lowest 2.14 for Color of normal stoma. The Std. Deviation is (.875, .938 and .981 were respectively for item four, five and six. Highest median value is 3.00 and highest mode value is 2 .

Knowledge regarding Normal Stoma

\begin{tabular}{|l|c|c|c|c|c|}
\hline \multicolumn{1}{|c|}{ Items } & N & Mean & Median & Mode & $\begin{array}{c}\text { Std. } \\
\text { Deviation }\end{array}$ \\
\hline Color of normal stoma & 150 & 2.14 & 2.00 & 2 & .875 \\
\hline Appearance of normal stoma & 150 & 2.45 & 2.00 & 2 & .938 \\
\hline Normal peristomal skin condition & 150 & 2.53 & 3.00 & 2 & .981 \\
\hline
\end{tabular}

Table 6

Table 7 shows that the participant response regarding daily care practices of stoma and results revealed that regarding item seven which is "Handwashing before procedure?" and majority $100(66.7 \%)$ wash their hand before procedure and $50(33.3 \%)$ did not wash their hands before any procedure regarding stoma care. Item eight is "Handwashing after procedure?" and participants response as majority $92(61.3 \%)$ wash their hand after procedure and $58(38.7 \%)$ did not wash their hands after any procedure regarding stoma care. Item nine is "Deal physical problem related to stoma?" and results $86(57.3 \%)$ deal problem related stoma $64(42.7 \%)$.

\begin{tabular}{|c|c|c|c|c|}
\hline \multicolumn{5}{|c|}{ Daily care practices } \\
\hline Items & Yes F & $\mathbf{F \%}$ & No $F$ & F\% \\
\hline Handwashing before procedure? & 100 & $66.7 \%$ & 50 & $33.3 \%$ \\
\hline Handwashing after procedure? & 92 & 61.3 & 58 & $38.7 \%$ \\
\hline Deal physical problem related to stoma? & 86 & $57.3 \%$ & 64 & $42.7 \%$ \\
\hline
\end{tabular}

Table 7 
Table 8 show that mean, median, mode and standard deviation of three items of questionnaire to assess the participants knowledge regarding stoma care and the mean is 1.33 for Handwashing before procedure?" then 1.39 for Handwashing after procedure? and highest 1.43 for Deal physical problem related to stoma? The Std. Deviation is $(.473, .489$ and .496 were respectively for item seven, eight and nine. Highest median value is 1.00 and highest mode value is 1 .

Daily care practices

\begin{tabular}{|l|c|c|c|c|c|}
\hline \multicolumn{1}{|c|}{ Items } & $\mathbf{N}$ & Mean & Median & Mode & $\begin{array}{c}\text { Std. } \\
\text { Deviation }\end{array}$ \\
\hline Handwashing before procedure? & 150 & 1.33 & 1.00 & 1 & .473 \\
\hline Handwashing after procedure? & 150 & 1.39 & 1.00 & 1 & .489 \\
\hline Deal physical problem related to stoma? & 150 & 1.43 & 1.00 & 1 & .496 \\
\hline
\end{tabular}

Table 8

Table 9 shows that the participant response regarding practices regarding physical problem and management and results revealed that regarding item ten which is "Practice of emptying stoma pouch?" and only 21 (14.0\%) go with totally filled, $52(34.7 \%)$ response as half-filled, $58(38.7 \%)$ response as $1 / 3$ rd filled and $19(12.7 \%)$ were empty there stoma bag while $<1 / 3$ rd filled. Item eleven is "Technique of cleaning stoma?" and participants response as majority $81(54 \%)$ use technique as periphery to center and only $69(46 \%)$ were go Centre to periphery. Item twelve is "Present physical problems?" and results revealed that the only $31(20.7 \%)$ have leakage problem, majority $74(49.3 \%)$ have peristomal, $28(18.7 \%)$ have skin irritation problem and only 17 (11.3\%) odor problem. Results revealed that regarding item thirteen which is "Practice regarding physical problem" and only $28(14.0 \%)$ go with solving peristomal skin irritation, $56(37.3 \%)$ response as Use of stoma powder to control odor, 51 (34\%) response as attend stoma clinic to manage the problem and $15(10 \%)$ were clean stoma and change pouch if liquid seeps under barrier. Item fourteen is "Practice regarding solving leakage?" and participants response as majority $37(24.7 \%)$ reducing size of aperture of flange of pouch and only $70(46.7 \%)$ were use 2-piece pouch $30(20 \%)$ Check adhesive pad for proper seal and $13(8.7 \%)$ were go with others. Item fifteen is "Practice regarding solving odor?" and results revealed that the only $27(18 \%)$ have Change diet, majority $49(32.7 \%)$ have Increased fluid intake, $49(32.7 \%)$ have Use deodorant and only $25(16.7 \%)$ do others to solve odor.

Practices regarding Physical Problem and management
\begin{tabular}{|l|c|c|c|c|c|c|c|c|}
\hline \multicolumn{1}{|c|}{ Items } & $\mathbf{1 ~ F}$ & $\mathbf{F \%}$ & $\mathbf{2}$ F & $\mathbf{F \%}$ & $\mathbf{3 ~ F}$ & $\mathbf{F \%}$ & $\mathbf{4 ~ F}$ & $\mathbf{F \%}$ \\
\hline Practice emptying stoma pouch? & 21 & $14.0 \%$ & 52 & $34.7 \%$ & 58 & $38.7 \%$ & 19 & 12.7 \\
\hline Technique of cleaning stoma? & 81 & $54 \%$ & 69 & $46 \%$ & 0 & $0 \%$ & 0 & $0 \%$ \\
\hline Present physical problems & 31 & $20.7 \%$ & 74 & $49.3 \%$ & 28 & $18.7 \%$ & 17 & $11.3 \%$ \\
\hline Practice regarding physical.... & 28 & $18.7 \%$ & 56 & $37.3 \%$ & 51 & $34 \%$ & 15 & $10 \%$ \\
\hline Practice regarding solving .... & 37 & $24.7 \%$ & 70 & $46.7 \%$ & 30 & $20 \%$ & 13 & 8.7 \\
\hline Practice regarding solving odor & 27 & $18 \%$ & 49 & $32.7 \%$ & 49 & $32.7 \%$ & 25 & $16.7 \%$ \\
\hline
\end{tabular}

Totally filled $=1$, Half-filled $=2,1 / 3 \mathrm{rd}$ filled $=3,<1 / 3 \mathrm{rd}$ filled $=4$

Periphery to center $=1$, Centre to periphery $=2$

Leakage $=1$, Peristomal $=2$, Skin irritation $=3$, Odor $=4$

Solving peristomal skin irritation $=1$, Use of stoma powder $=2$, Attend stoma clinic $=3$

Clean stoma and change pouch if liquid seeps under barrier $=4$

Reducing size of aperture of flange of pouch $=1$, Use 2-piece pouch $=2$,

Check adhesive pad for proper seal $=3$, Others $=4$

Table 9

Table 10 shows that the statistics (mean, median, mode and standard deviation) of 6 items of questionnaire regarding practices of stoma care and results revealed that the highest mean value is 2.50 of item ten which is "Practice of emptying stoma pouch?" and comparatively lowest mean value is 1.46 for item eleven which is "Technique of cleaning stoma?". The mean value for others item is between 1.46-2.50 respectively. Median and mode value of most of items is 2 and highest is 3 . Standard deviation value .974 is highest and comparatively .500 is low.

Practices regarding Physical Problem and management

\begin{tabular}{|l|c|c|c|c|c|}
\hline \multicolumn{1}{|c|}{ Items } & $\mathbf{N}$ & Mean & Median & Mode & $\begin{array}{c}\text { Std. } \\
\text { Deviation }\end{array}$ \\
\hline Practice of emptying stoma pouch? & 150 & 2.50 & 3.00 & 3 & .888 \\
\hline Technique of cleaning stoma? & 150 & 1.46 & 1.00 & 1 & .500 \\
\hline Present physical problems & 150 & 2.21 & 2.00 & 2 & .900 \\
\hline
\end{tabular}




\begin{tabular}{|l|l|l|l|l|l|}
\hline Practice regarding physical problem & 150 & 2.35 & 2.00 & 2 & .898 \\
\hline Practice regarding solving leakage & 150 & 2.13 & 2.00 & 2 & .885 \\
\hline Practice regarding solving odor & 150 & 2.48 & 2.00 & 2 & .974 \\
\hline
\end{tabular}

Table 10

Table 11 shows that the participants response regarding stoma self-care efficacy and results revealed that regarding item sixteen which is "Apply the stoma collection materials before leakages appear" and only $16(10.7 \%)$ were not confident, $33(22 \%)$ were slightly confident, majority 45 (30\%) were fairly confident, $44(28 \%)$ were highly confident and only $14(9.3 \%)$ were extremely confident. Item seventeen is "Prevent having leakages" and participants response as only $8(5.3 \%)$ were not confident, $32(21.3 \%)$ were slightly confident, majority $43(28.7 \%)$ were fairly confident, $40(26.7 \%)$ were highly confident and only $27(18 \%)$ were extremely confident. Item eighteen is "Take care of the stoma in the right way at home" and participants response as only $1(.7 \%)$ were not confident, $17(11.3 \%)$ were slightly confident, majority $66(44 \%)$ were fairly confident, $53(35 \%)$ were highly confident and only $13(8.7 \%)$ were extremely confident. Item nineteen is "Prevent having skin problems." and participants response as only $1(.7 \%)$ were not confident, $48(32 \%)$ were slightly confident, majority $42(28 \%)$ were fairly confident, $44(29.3 \%)$ were highly confident and only $15(10 \%)$ were extremely confident. Item twenty is "Prevent having stoma bleeding and damage" and participants response as only 30 (20\%) were not confident, $47(31.3 \%)$ were slightly confident, majority 36 (24\%) were fairly confident, $24(16 \%)$ were highly confident and only $13(8.7 \%)$ were extremely confident. Item twenty-one is "Apply the stoma collection materials in the way you learned to do." and participants response as only $25(16.7 \%)$ were not confident, 27 (18\%) were slightly confident, majority $42(28 \%)$ were fairly confident, 45 (30\%) were highly confident and only $11(7.3 \%)$ were extremely confident. Item twenty-two is "Prevent having obstruction" and participants response as only $1(.7 \%)$ were not confident, 33 (22\%) were slightly confident, majority 53 (35.3\%) were fairly confident, 54 (36\%) were highly confident and only $9(6 \%)$ were extremely confident. Item twenty-three is "Follow the nurse's instructions for handling the stoma." and participants response as only $0(0 \%)$ were not confident, $9(6 \%)$ were slightly confident, majority $77(51.3 \%)$ were fairly confident, $56(36.7 \%)$ were highly confident and only $9(6 \%)$ were extremely confident. Item twenty-four is "Follow the doctor's advice for taking care of your stoma and nutrition pattern" and participants response as only $16(10.7 \%)$ were not confident, $46(30.7 \%)$ were slightly confident, majority $53(35.3 \%)$ were fairly confident, $35(23.3 \%)$ were highly confident and only $0(0 \%)$ were extremely confident. Item twenty-five is "Take care of the stoma in the right way outdoors" and participants response as only $12(8 \%)$ were not confident, 39 (26\%) were slightly confident, majority 41 (27.3\%) were fairly confident, 41 $(27.3 \%)$ were highly confident and only $17(11.3 \%)$ were extremely confident.

Item twenty-six is "Take care of the stoma when you are ill." and participants response as only $16(10.7 \%)$ were not confident, $46(30.7 \%)$ were slightly confident, majority $53(35.3 \%)$ were fairly confident, $35(23.3 \%)$ were highly confident and only $0(0 \%)$ were extremely confident. Item twenty-seven is "Wear most of the clothes you like" and participants response as only $9(6 \%)$ were not confident, $25(16.7 \%)$ were slightly confident, majority 47 $(31.3 \%)$ were fairly confident, 60 (40\%) were highly confident and only $9(6 \%)$ were extremely confident. Item twenty-eight is "Carry out light duties in and around the house (for instance washing up and gardening)" and participants response as only $12(8 \%)$ were not confident, $28(18.7 \%)$ were slightly confident, majority $53(35.3 \%)$ were fairly confident, $45(30 \%)$ were highly confident and only $12(8 \%)$ were extremely confident.

\section{Self-Care Efficacy}

\begin{tabular}{|l|l|l|l|l|l|l|l|l|l|l|}
\hline Items & $\begin{array}{l}\mathbf{1} \\
\mathbf{F}\end{array}$ & $\begin{array}{c}\mathbf{F} \\
\mathbf{\%}\end{array}$ & $\begin{array}{l}\mathbf{2} \\
\mathbf{F}\end{array}$ & $\begin{array}{l}\mathbf{F} \\
\mathbf{\%}\end{array}$ & $\mathbf{3 ~ F}$ & $\begin{array}{l}\mathbf{F} \\
\mathbf{\%}\end{array}$ & $\begin{array}{l}\mathbf{4} \\
\mathbf{F}\end{array}$ & $\begin{array}{c}\text { F } \\
\mathbf{\%}\end{array}$ & $\begin{array}{l}\mathbf{5 ~ F} \\
\mathbf{F}\end{array}$ \\
\hline Apply the stoma collection materials... & 16 & 10.7 & 33 & 22 & 45 & 30 & 44 & 28 & 14 & 9.3 \\
\hline Prevent having leakages. & 8 & 5.3 & 32 & 21.3 & 43 & 28.7 & 40 & 26.7 & 27 & 18 \\
\hline Take care of the stoma in the right ... & 1 & .7 & 17 & 11.3 & 66 & 44 & 53 & 35 & 13 & 8.7 \\
\hline Prevent having skin problems...... & 1 & .7 & 48 & 32 & 42 & 28 & 44 & 29.3 & 15 & 10 \\
\hline Prevent having stoma bleeding... & 30 & 20 & 47 & 31.3 & 36 & 24 & 24 & 16 & 13 & 8.7 \\
\hline Apply the stoma collection materials... & 25 & 16.7 & 27 & 18 & 42 & 28 & 45 & 30 & 11 & 7.3 \\
\hline Prevent having obstruction. & 1 & .7 & 33 & 22 & 53 & 35.3 & 54 & 36 & 9 & 6 \\
\hline Follow the nurse's instructions...... & 0 & 0 & 9 & 6 & 77 & 51.3 & 55 & 36.7 & 9 & 6 \\
\hline Follow the doctor's advice for taking. & 16 & 10.7 & 39 & 26 & 59 & 39.3 & 35 & 23.3 & 1 & .7 \\
\hline Take care of the stoma in the right... & 12 & 8 & 39 & 26 & 41 & 27.3 & 41 & 27.3 & 17 & 11.3 \\
\hline Take care of the stoma when you.... & 16 & 10.7 & 46 & 30.7 & 53 & 35.3 & 35 & 23.3 & 0 & 0 \\
\hline Wear most of the clothes you like & 9 & 6 & 25 & 16.7 & 47 & 31.3 & 60 & 40 & 9 & 6 \\
\hline Carry out light duties in and around... & 12 & 8 & 28 & 18.7 & 53 & 35.3 & 45 & 30 & 12 & 8 \\
\hline
\end{tabular}

Not confident $=1$, Slightly confident $=2$, Fairly confident $=3$, Highly confident $=4$, Extremely confident $=5$

Table 11 
Table 12 shows that the statistics (mean, median, mode and standard deviation) of 13 items of questionnaire regarding practices regarding stoma Self-Care Efficacy and results revealed that the highest mean value is 3.43 of item twenty-three which is "Follow the nurse's instructions for handling the stoma" and comparatively lowest mean value is 2.62 for item twenty which is "Prevent having stoma bleeding and damage". The mean value for others item is between 2.62-3.43 respectively. Median and mode value of most of items is 3 and highest is 4 . Standard deviation value 1.219 is highest and comparatively .698 is low.

\begin{tabular}{|l|c|c|c|c|c|}
\hline \multicolumn{1}{|c|}{ Items } & $\mathbf{N}$ & Mean & Median & Mode & $\begin{array}{c}\text { Std. } \\
\text { Deviation }\end{array}$ \\
\hline Apply the stoma collection materials...... & 150 & 3.03 & 3.00 & 3 & 1.144 \\
\hline Prevent having leakages. & 150 & 3.31 & 3.00 & 3 & 1.152 \\
\hline Take care of the stoma in the right way... & 150 & 3.40 & 3.00 & 3 & .827 \\
\hline Prevent having skin problems.... & 150 & 3.16 & 3.00 & 2 & 1.011 \\
\hline Prevent having stoma bleeding and damage & 150 & 2.62 & 2.00 & 2 & 1.219 \\
\hline Apply the stoma collection materials in..... & 150 & 2.93 & 3.00 & 4 & 1.202 \\
\hline Prevent having obstruction. & 150 & 3.25 & 3.00 & 3 & .889 \\
\hline Follow the nurse's instructions for....... & 150 & 3.43 & 3.00 & 3 & .698 \\
\hline Follow the doctor's advice for taking care... & 150 & 2.77 & 3.00 & 3 & .949 \\
\hline Take care of the stoma in the right way..... & 150 & 3.08 & 3.00 & 3 & 1.144 \\
\hline Take care of the stoma when you are ill. & 150 & 2.71 & 3.00 & 3 & .944 \\
\hline Wear most of the clothes you like & 150 & 3.23 & 3.00 & 4 & .999 \\
\hline Carry out light duties in and around...... & 150 & 3.11 & 3.00 & 3 & 1.059 \\
\hline
\end{tabular}

Table 12

Figure 8 shows that the participants response regarding item one which was "Black colored stoma is normal" 60 (40\%) response as yes, which is correct, 59 (39.3\%) go with no and only $31(20.7 \%)$ response as not know the color of stoma.

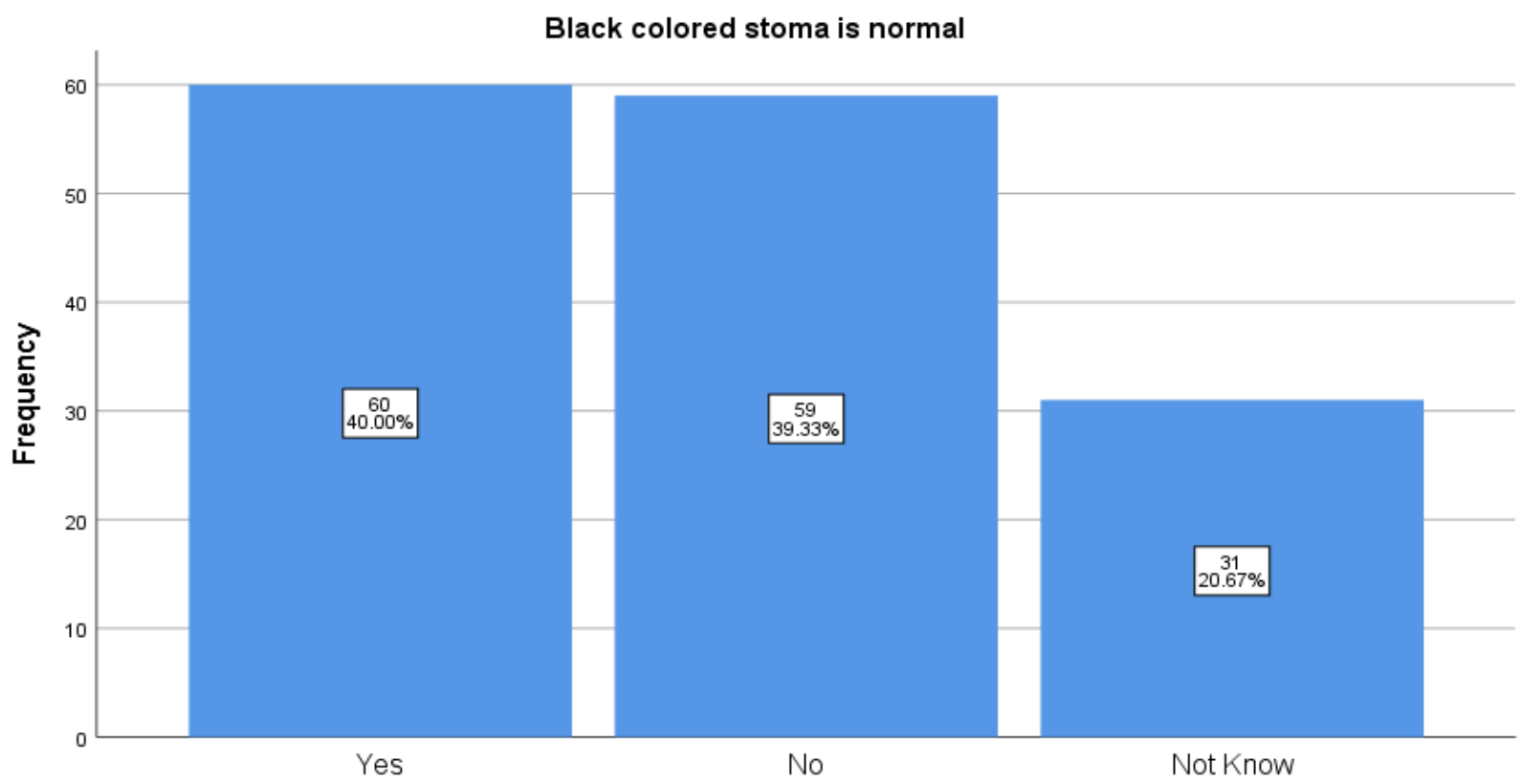

Black colored stoma is normal

Figure 8

Figure 9 shows that the participants response regarding item two which is "stoma protruded $>2$ inch is normal" and majority $60(40 \%)$ response correctly as yes, $52(34.7 \%)$ response wrongly as no and $38(25.3 \%)$ were not know the stoma protruded $>2$ inch is normal. 


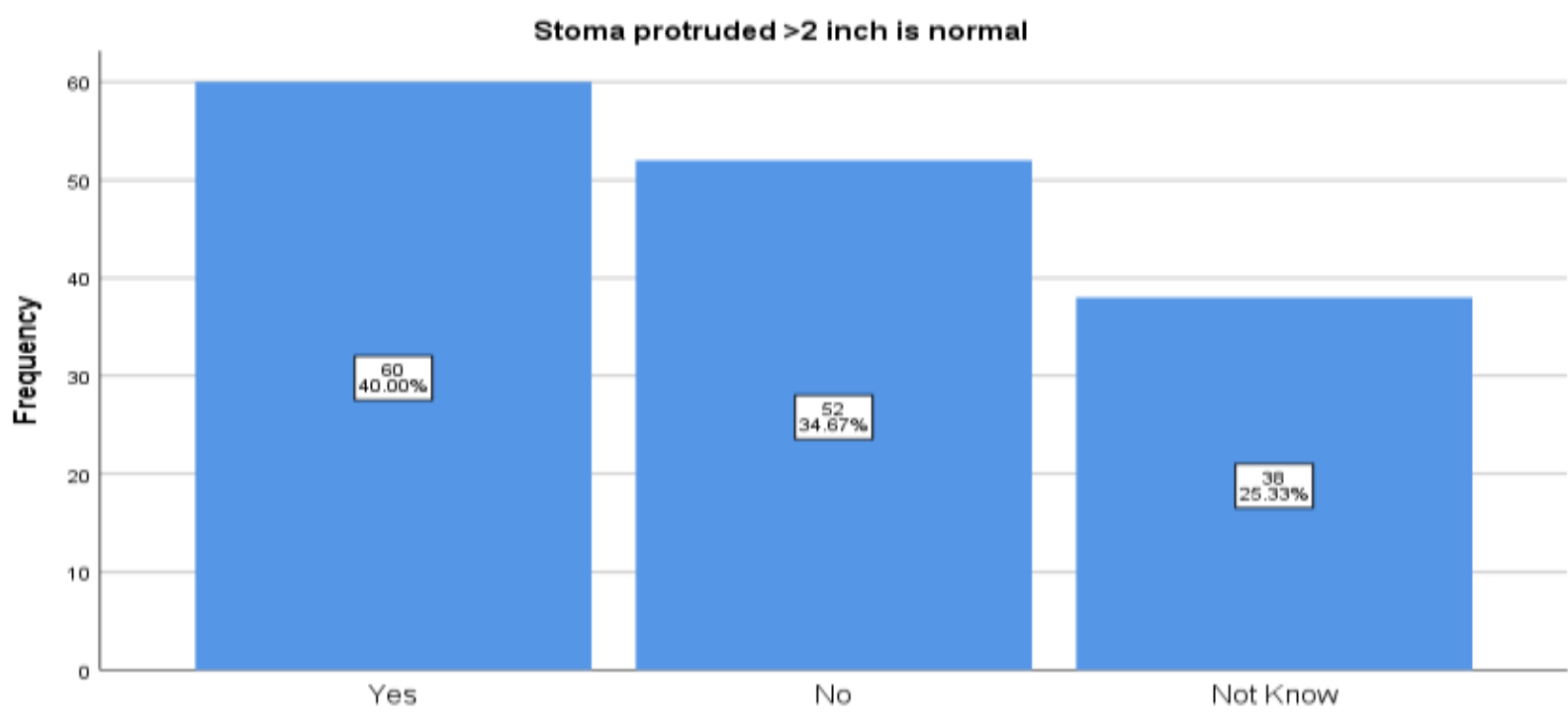

Stoma protruded $>2$ inch is normal

Figure 9

Figure 10 shows that the participants response regarding three which is "Continued bleeding from inside stoma for $>10 \mathrm{~min}$ is normal" as majority $88(58.7 \%)$ were go with yes, $54(36 \%)$ response as yes and only $8(5.3 \%)$ did not know about it.

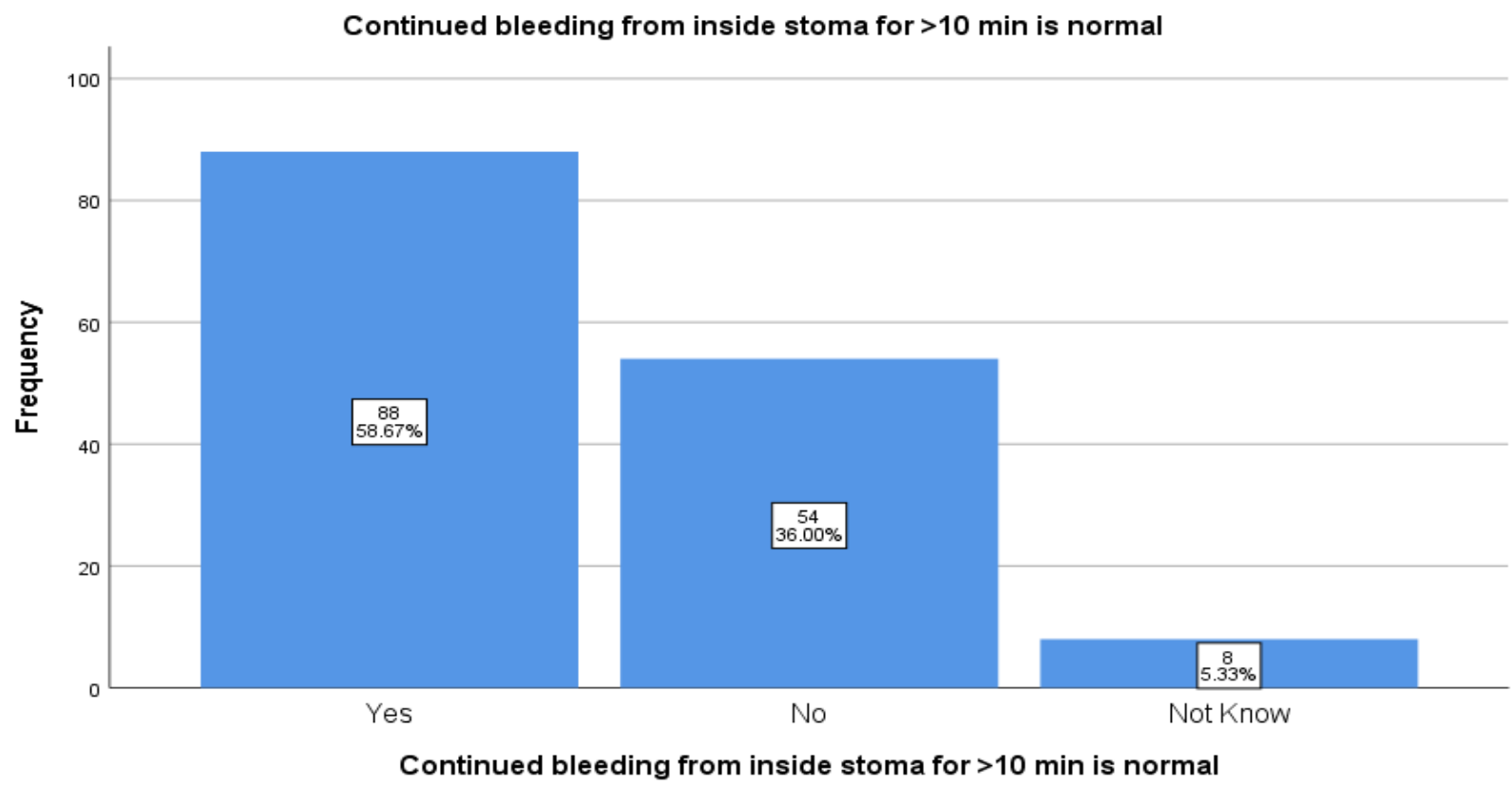

Figure 10

Figure 11 shows that the participants response regarding the knowledge of stoma care and results revealed regarding the item four which is "Color of normal stoma" and participants response as $38(25.3 \%)$ go with red, majority $63(42 \%)$ go with pale, $39(26 \%)$ response as black and only $10(6.7 \%)$ response as not know about the color of normal stoma. 


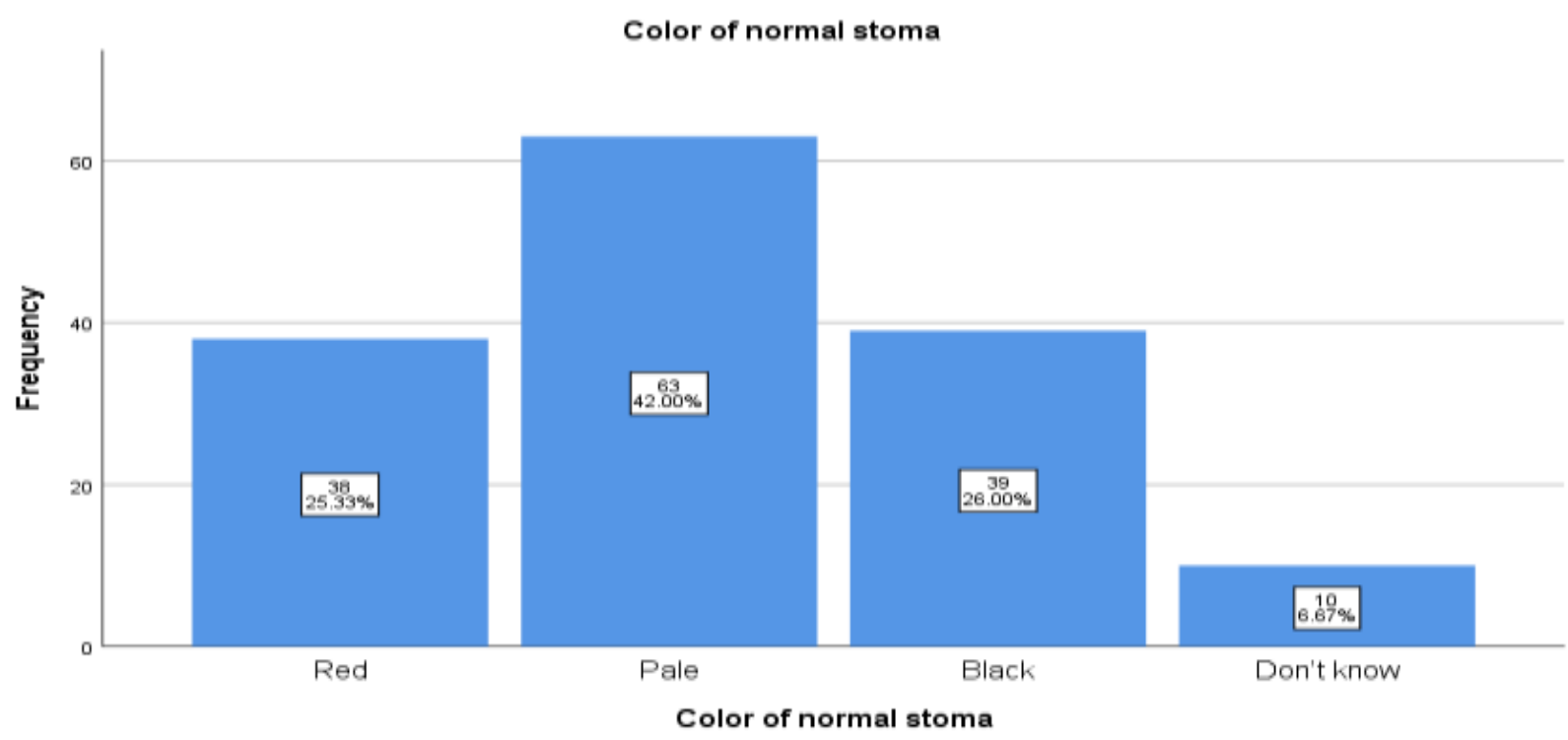

Figure 11

Figure 12 shows that the participants response regarding item five which is "Appearance of normal stoma" and participants response as $25(16.7 \%)$ go with shiny and moist, majority $55(36.7 \%)$ response as has nodules, 48 (32\%) response as has cuts and torn and only 22 did not know about the appearance of normal stoma.

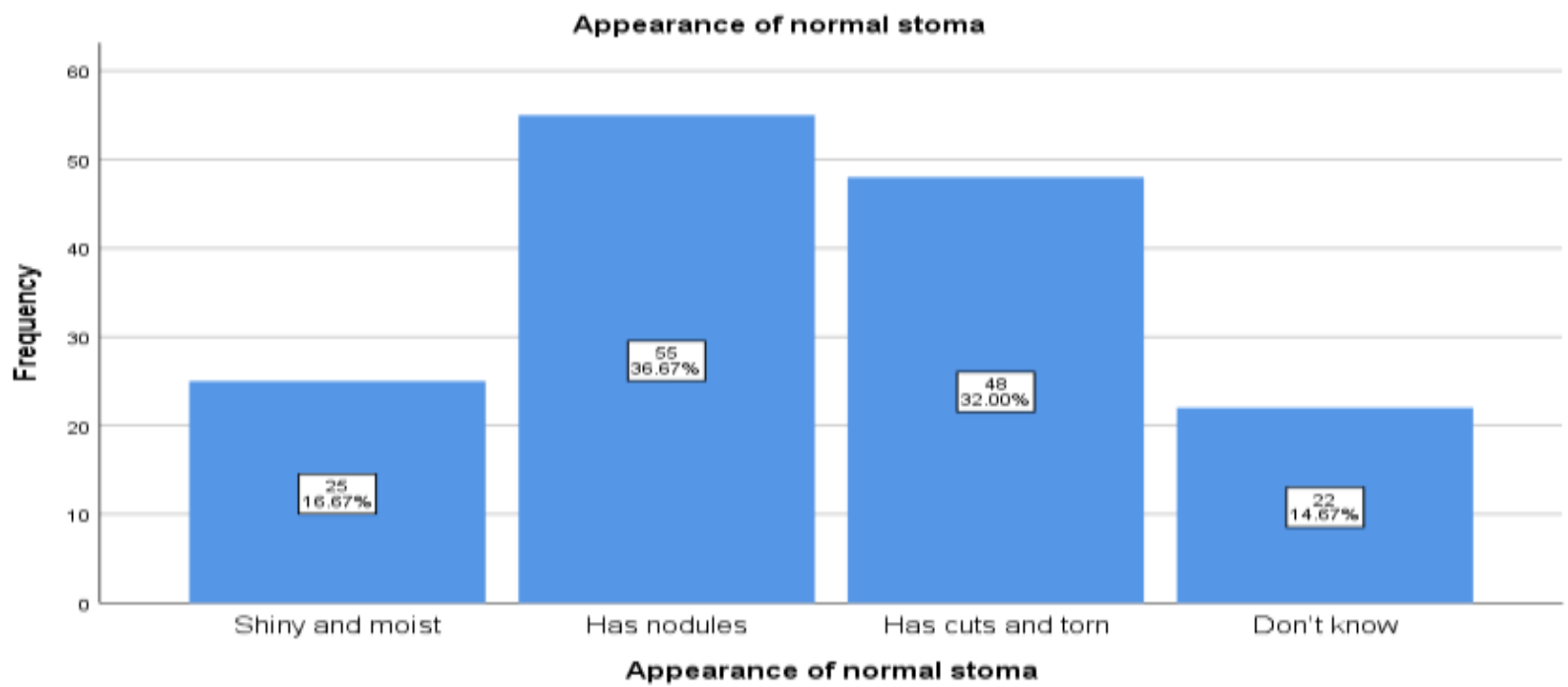

Figure 12

Figure 13 shows that the participants response regarding item six which is "Deal physical problem related to stoma?" and results $86(57.3 \%)$ deal problem related stoma $64(42.7 \%)$. 


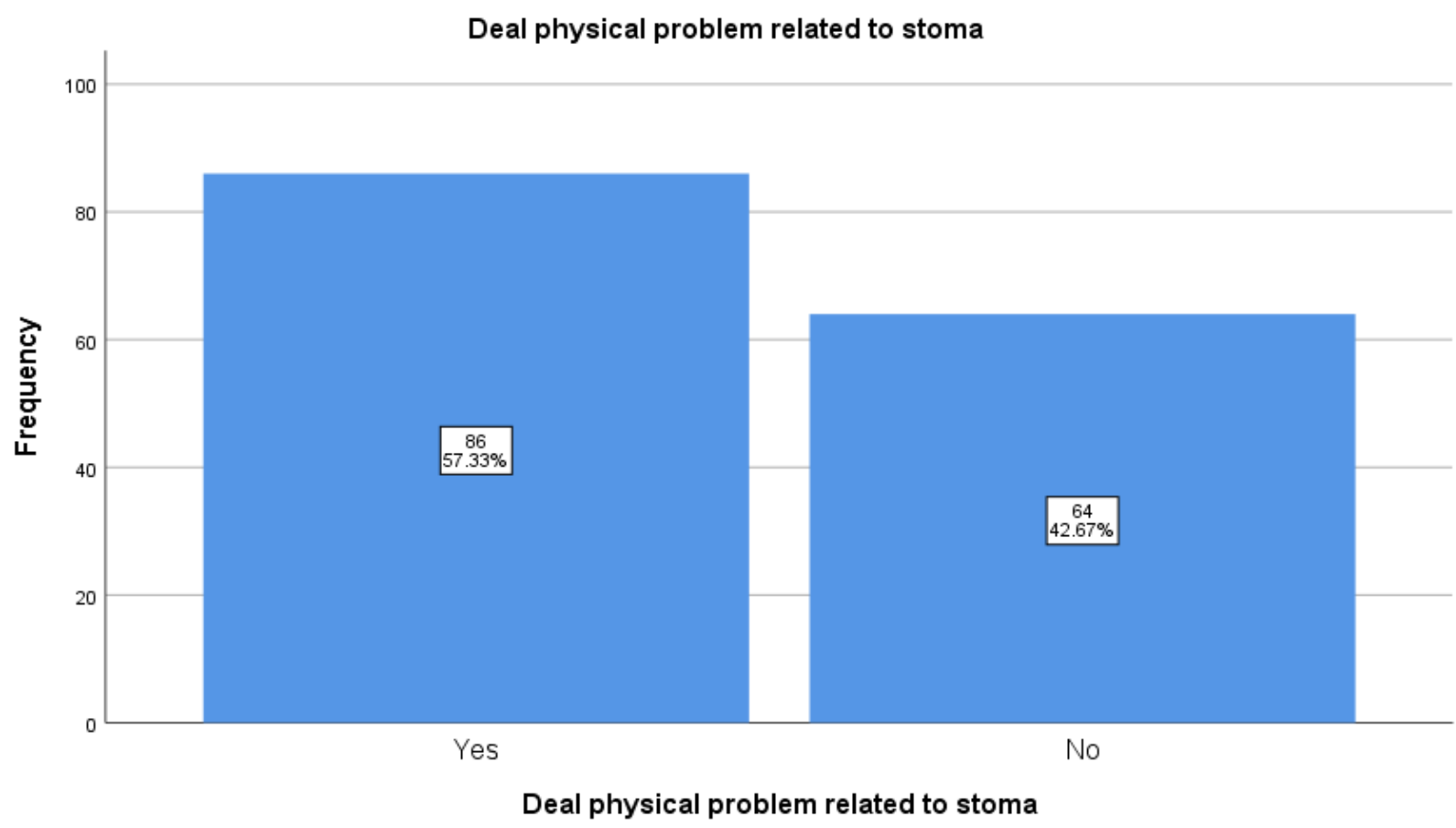

Figure 13

Figure 14 shows that the participants response regarding item seven which is "Normal peristomal skin condition" and participants response as $25(16.7 \%)$ go with Similar to other skin, majority $49(32.7 \%)$ response as red, 48 (32\%) response as painful to touch and only $22(18.7 \%)$ did not know about the normal peristomal skin condition.

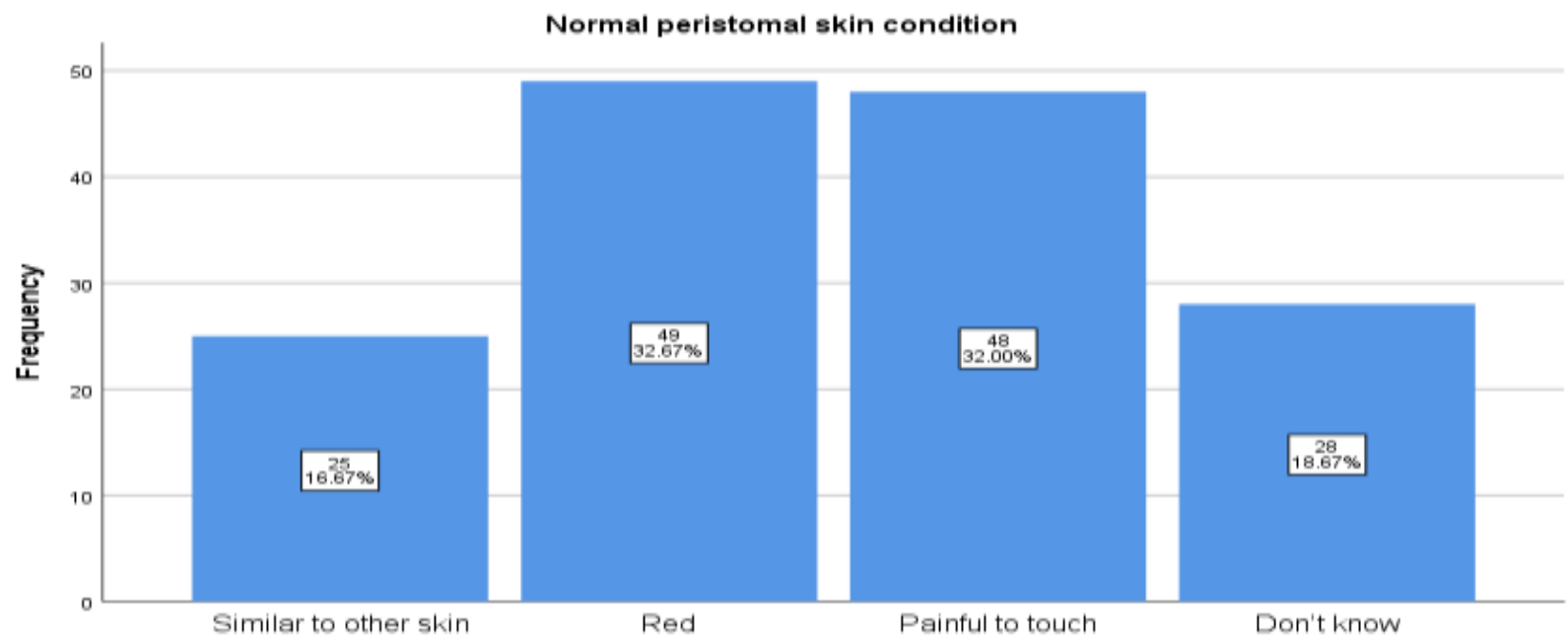

Normal peristomal skin condition

Figure 14

Figure 15 shows that the participant response regarding daily care practices of stoma and results revealed that regarding item eight which is "Handwashing before procedure?" and majority $100(66.7 \%)$ wash their hand before procedure and $50(33.3 \%)$ did not wash their hands before any procedure regarding stoma care. 


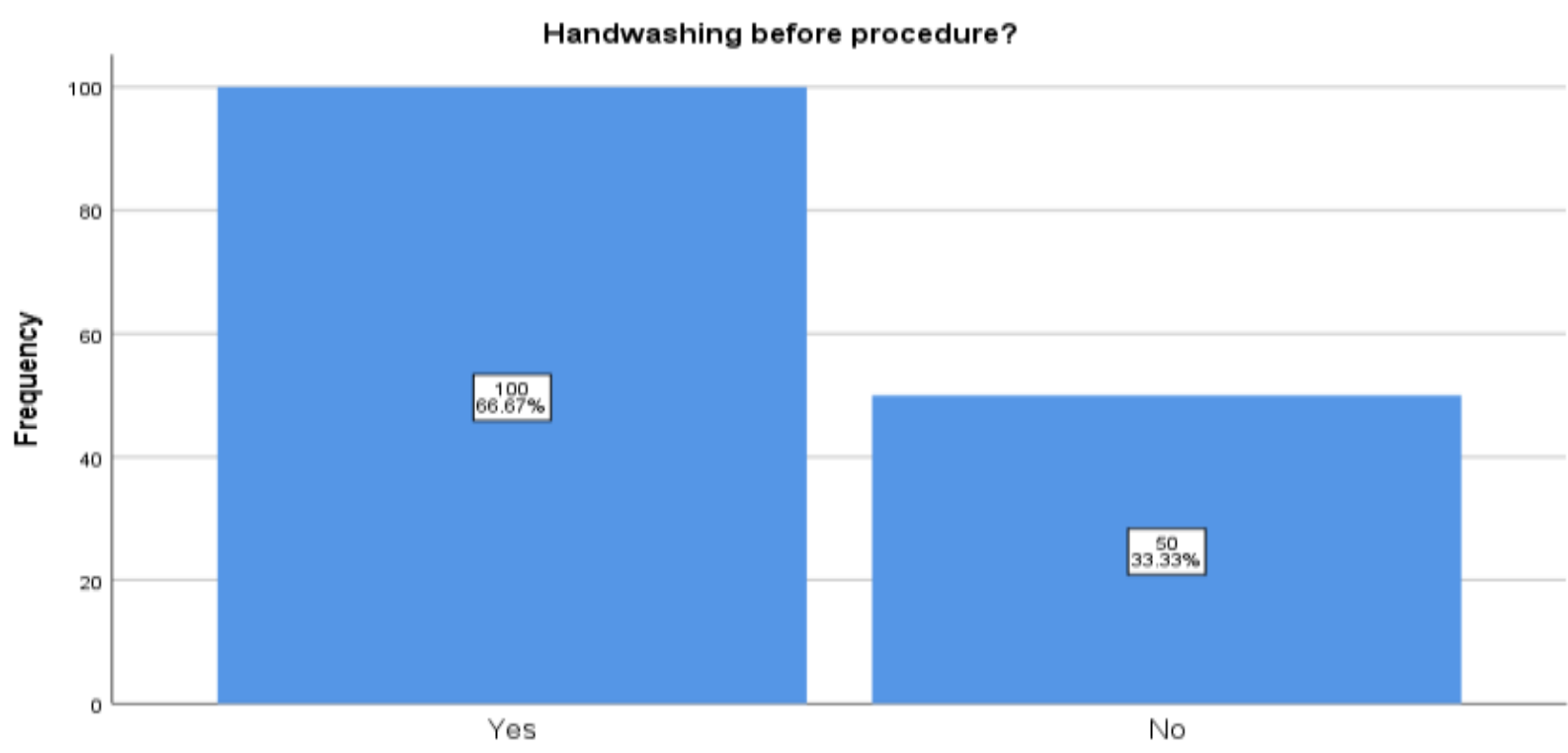

Handwashing before procedure?

Figure 15

Figure 16 shows that the participants response regarding item nine which is "Handwashing after procedure?" and participants response as majority $92(61.3 \%)$ wash their hand after procedure and $58(38.7 \%)$ did not wash their hands after any procedure regarding stoma care.

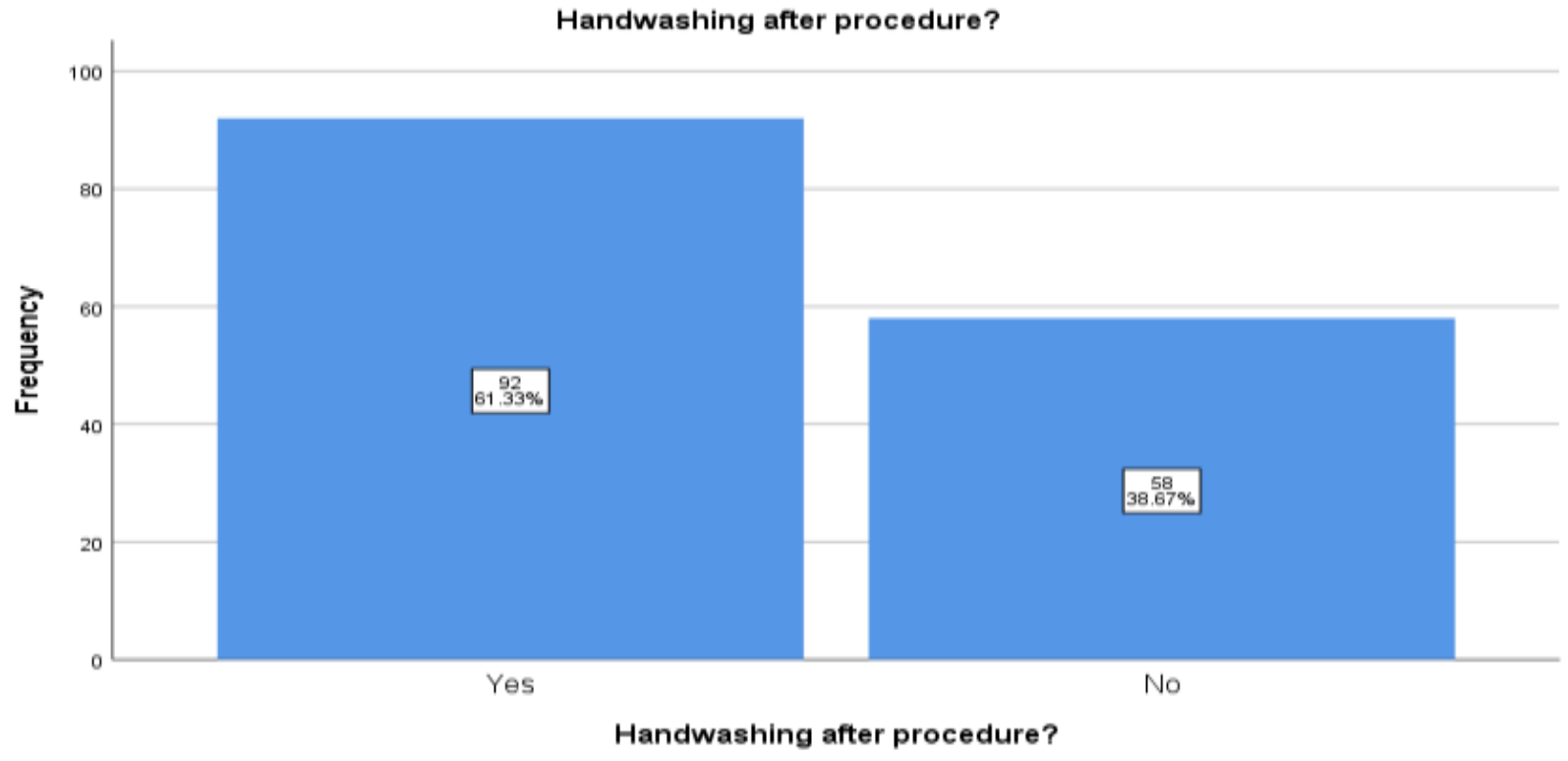

Figure 16

Figure 17 shows that the participant response regarding practices regarding physical problem and management and results revealed that regarding item ten which is "Practice of emptying stoma pouch?" and only 21 (14.0\%) go with totally filled, $52(34.7 \%)$ response as half-filled, $58(38.7 \%)$ response as $1 / 3$ rd filled and $19(12.7 \%)$ were empty there stoma bag while $<1 / 3$ rd filled. 


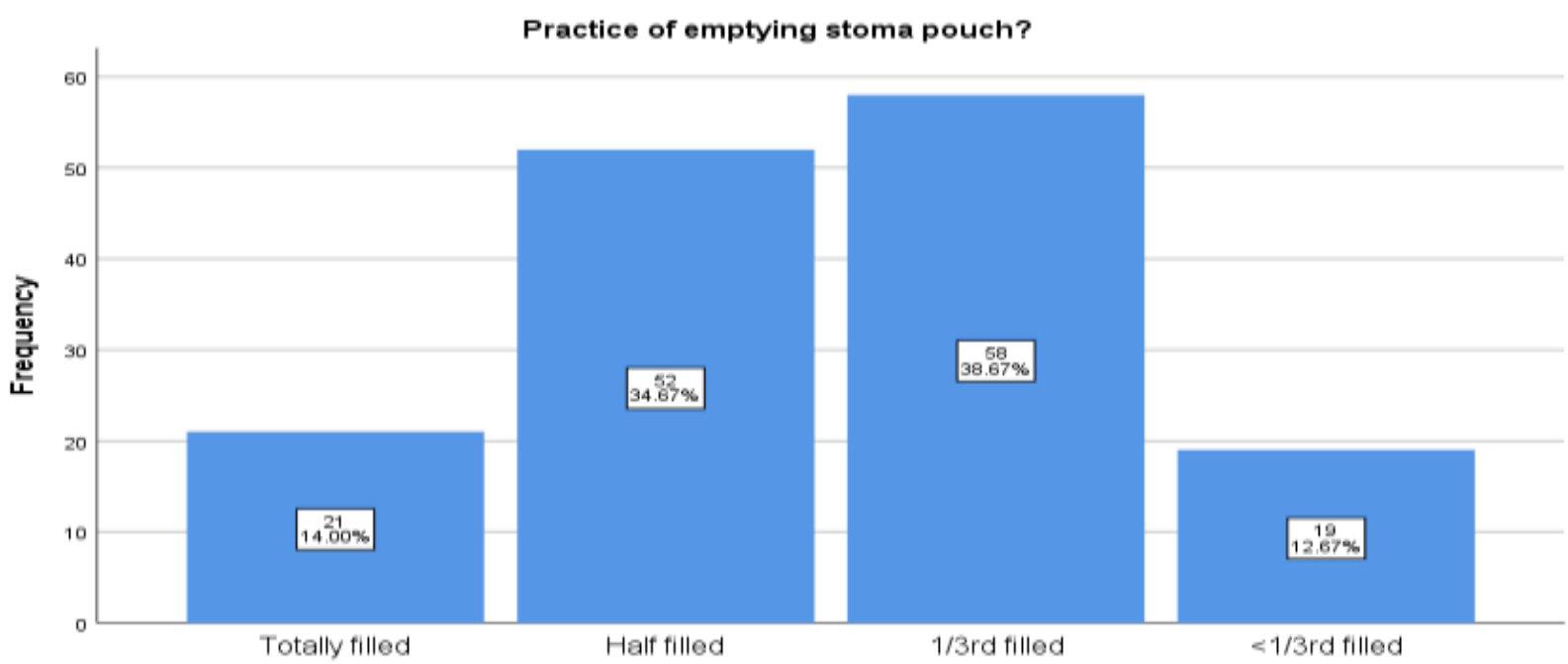

Practice of emptying stoma pouch?

Figure 17

Figure 18 shows that the results regarding item eleven which is "Technique of cleaning stoma?" and participants response as majority $81(54 \%)$ use technique as periphery to center and only $69(46 \%)$ were go Centre to periphery.

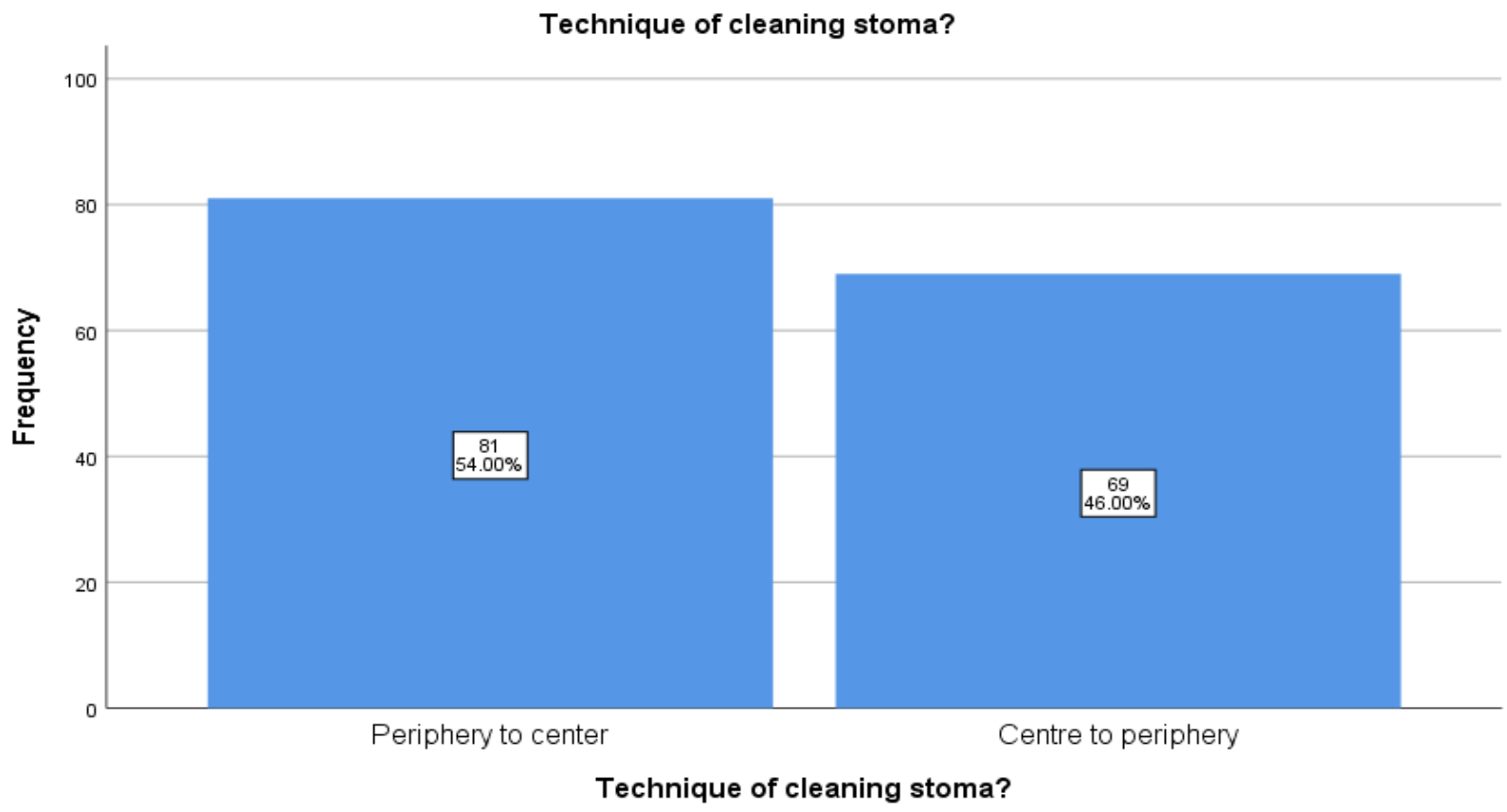

Figure 18

Figure 19 shows that the results regarding item twelve which is "Present physical problems?" and results revealed that the only $31(20.7 \%)$ have leakage problem, majority $74(49.3 \%)$ have peristomal, $28(18.7 \%)$ have skin irritation problem and only $17(11.3 \%)$ odor problem. 


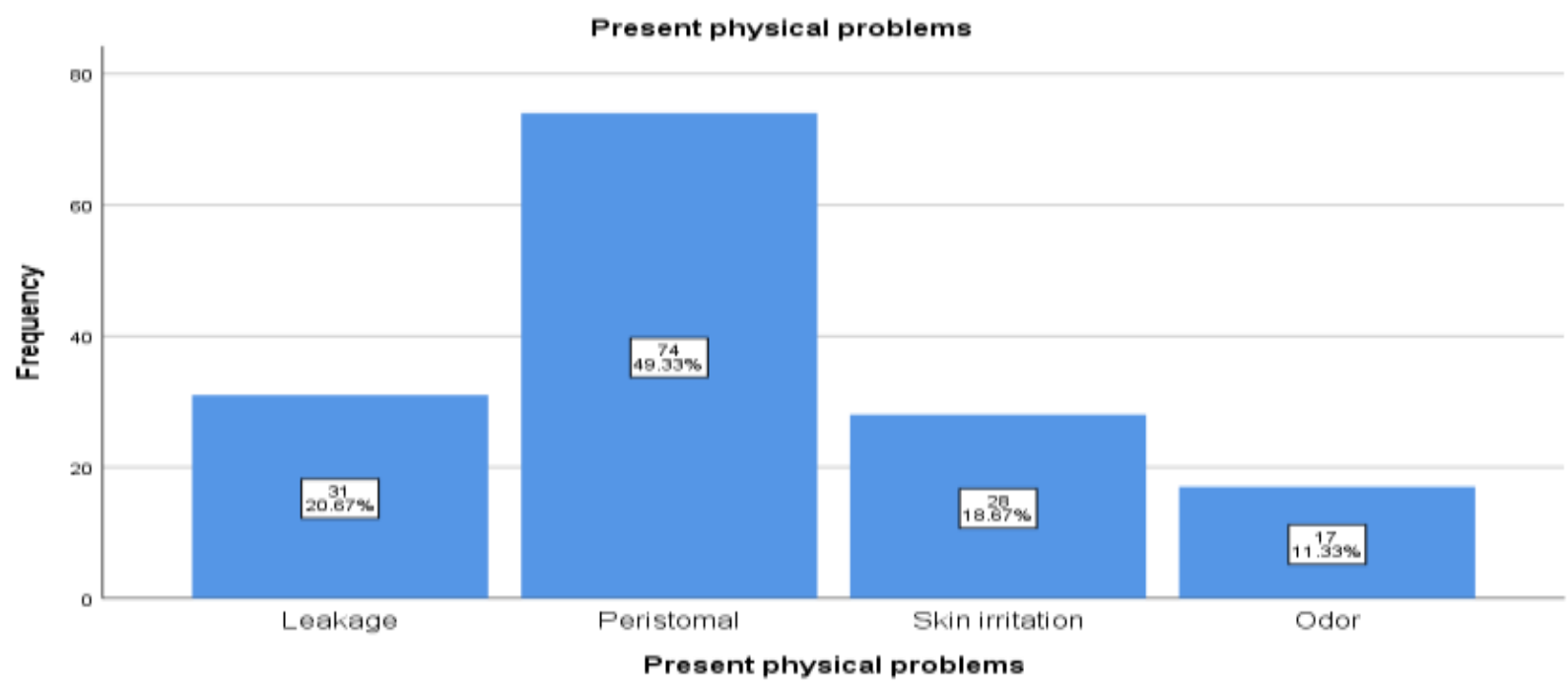

Figure 19

Figure 20 shows that the results regarding item results revealed that regarding item thirteen which is "Practice regarding physical problem" and only 28 (14.0\%) go with solving peristomal skin irritation, 56 (37.3\%) response as Use of stoma powder to control odor, $51(34 \%)$ response as attend stoma clinic to manage the problem and 15 $(10 \%)$ were clean stoma and change pouch if liquid seeps under barrier.

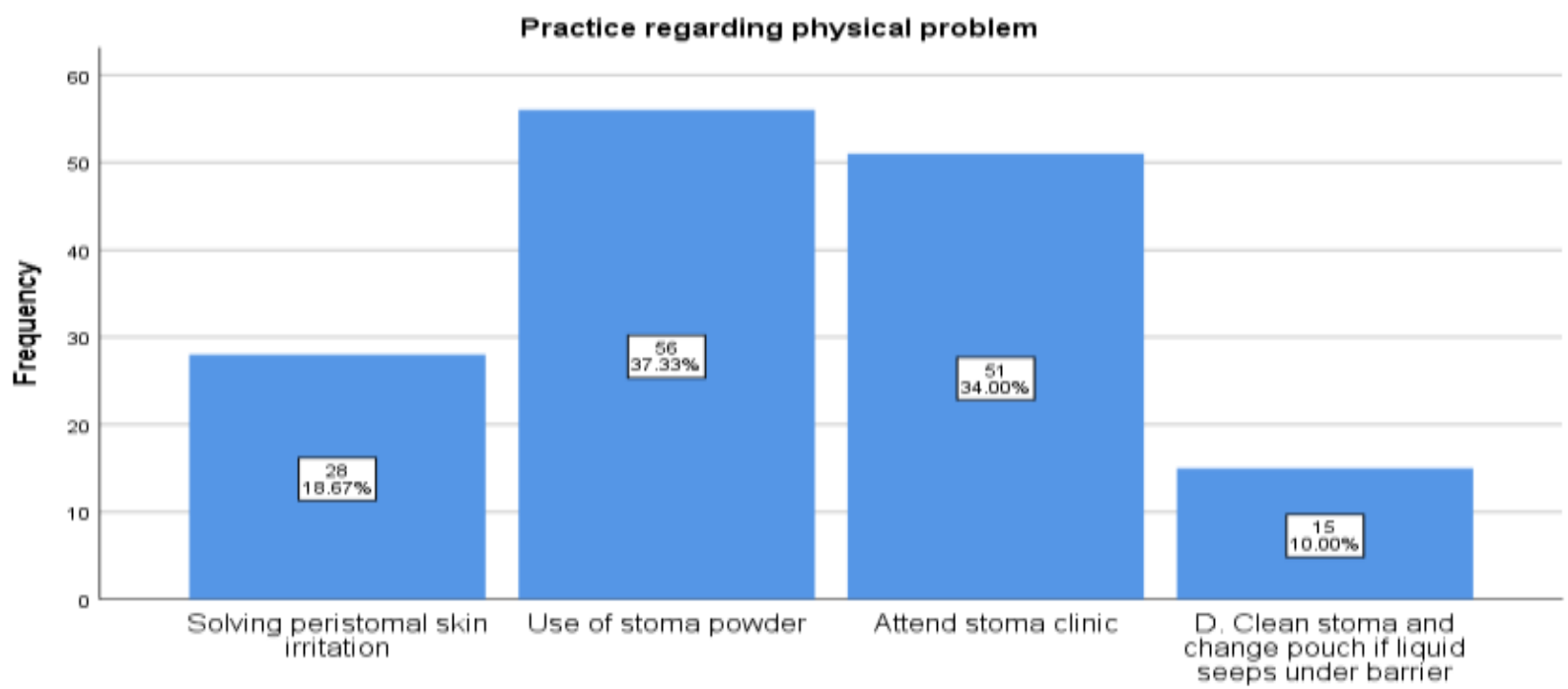

Practice regarding physical problem

Figure 20

Figure 21 shows that the results regarding item fourteen which is "Practice regarding solving leakage?" and participants response as majority $37(24.7 \%)$ reducing size of aperture of flange of pouch and only $70(46.7 \%)$ were use 2-piece pouch $30(20 \%)$ Check adhesive pad for proper seal and $13(8.7 \%)$ were go with others. 


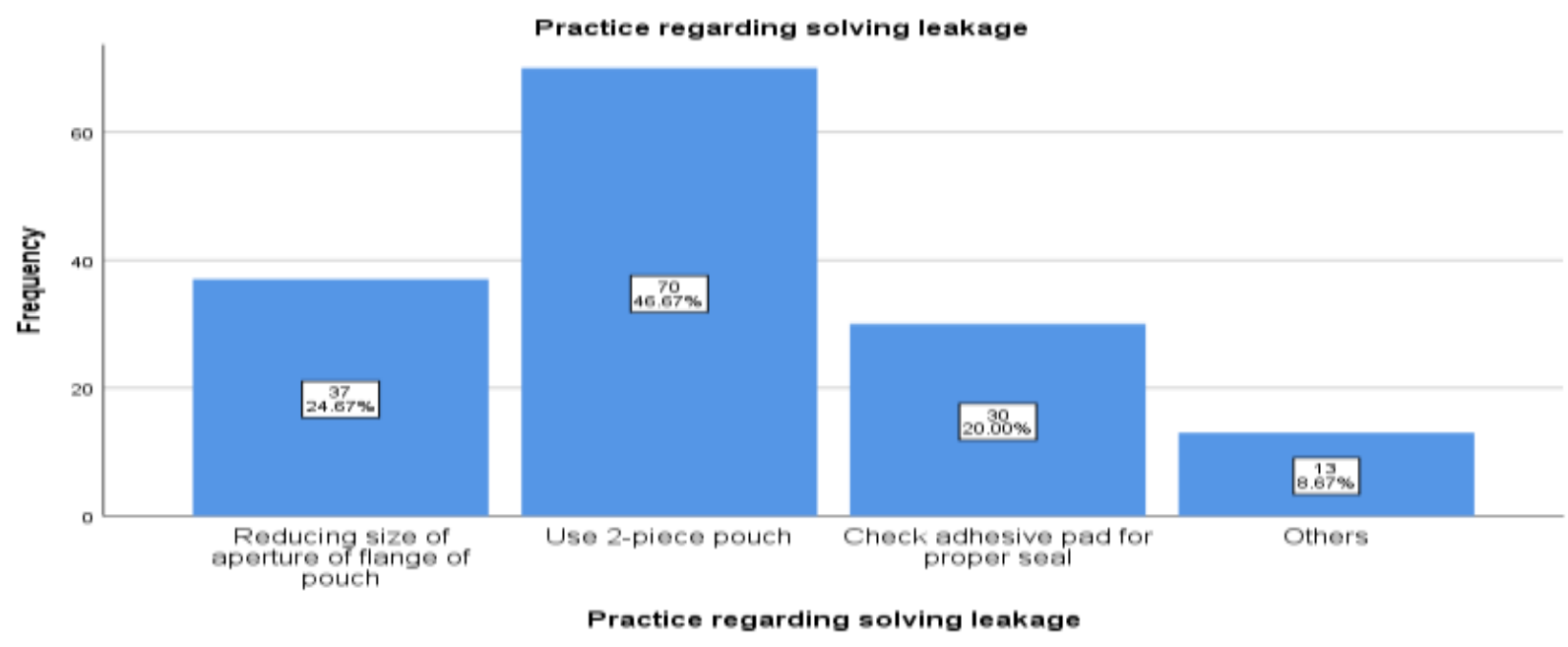

Figure 21

Figure 22 shows that the results regarding item fifteen which is "Practice regarding solving odor?" and results revealed that the only 27 (18\%) have Change diet, majority 49 (32.7\%) have Increased fluid intake, 49 (32.7\%) have Use deodorant and only 25 (16.7\%) do others to solve odor.

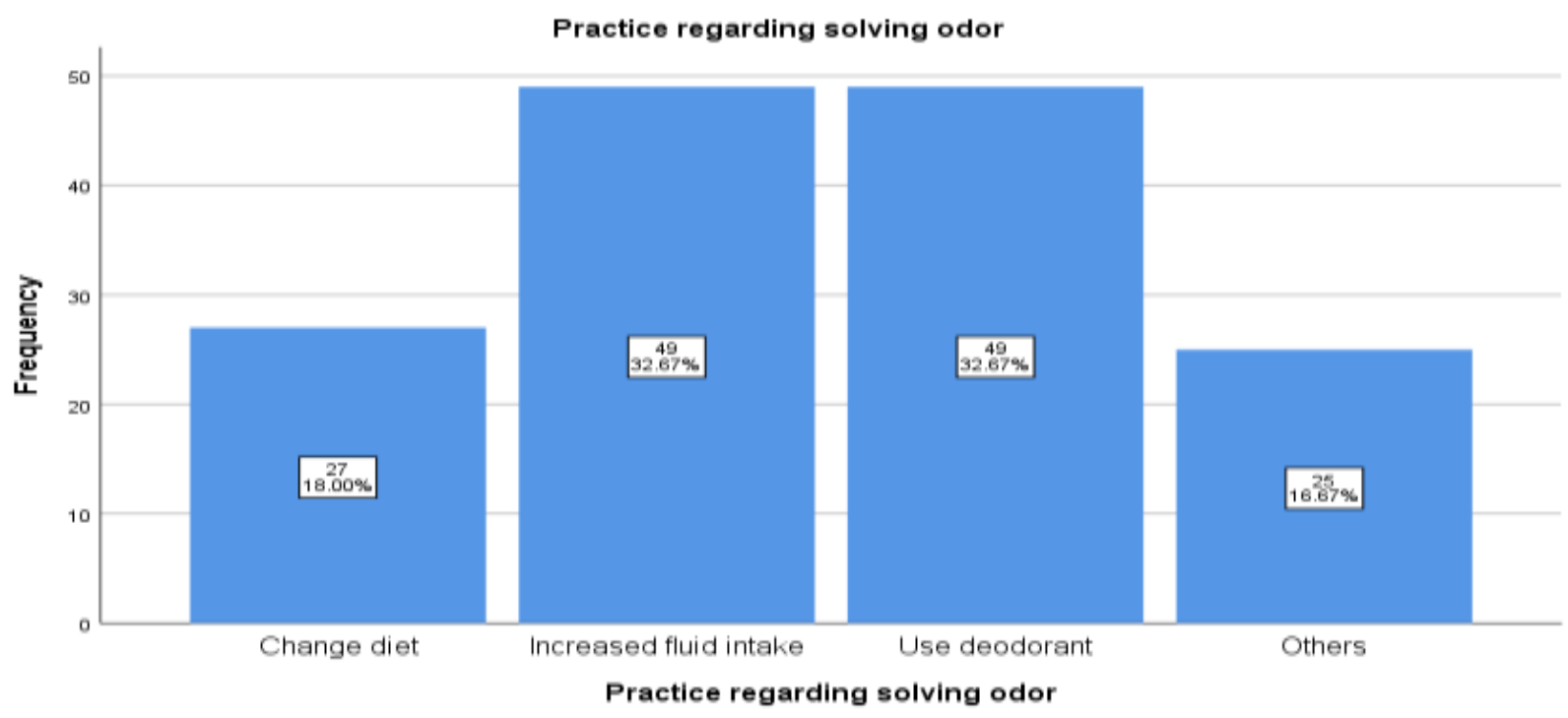

Figure 22

Figure 23 shows that the participants response regarding stoma self-care efficacy and results revealed that regarding item sixteen which is "Apply the stoma collection materials before leakages appear" and only $16(10.7 \%)$ were not confident, 33 (22\%) were slightly confident, majority 45 (30\%) were fairly confident, $44(28 \%)$ were highly confident and only 14 (9.3\%) were extremely confident. 


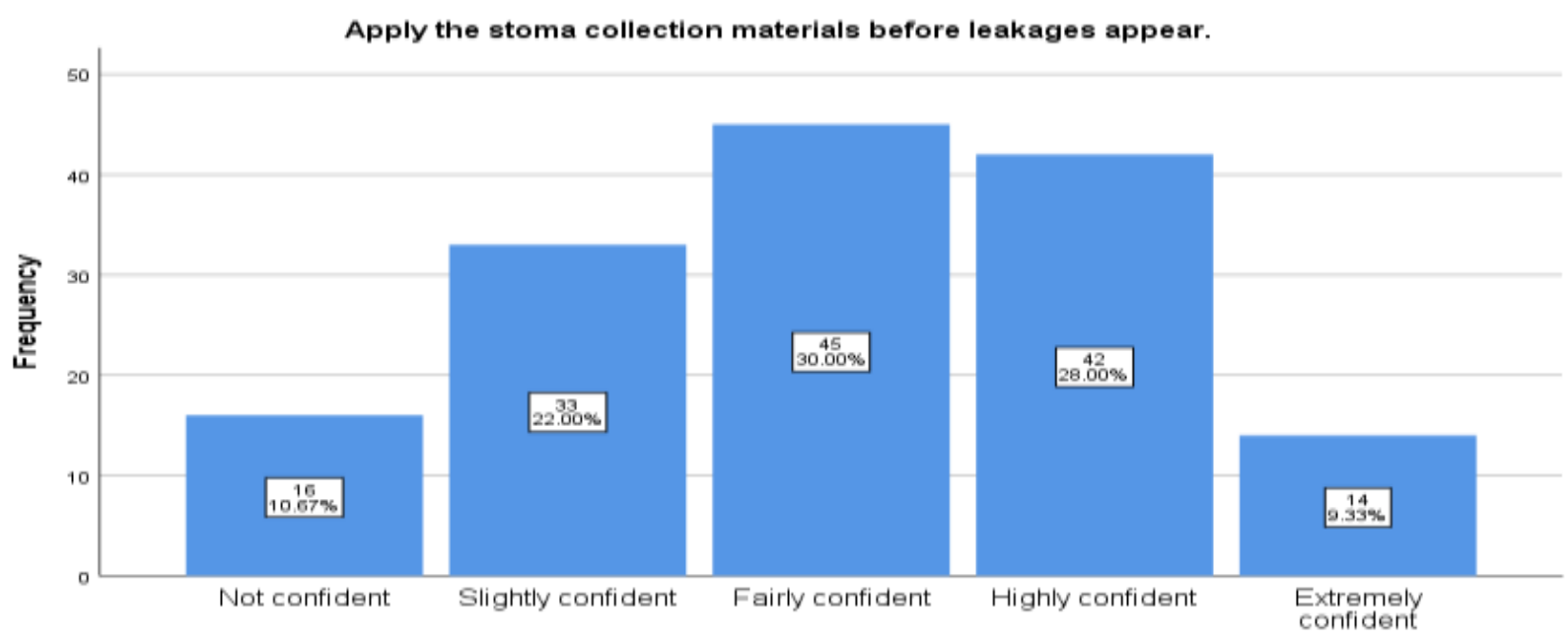

Apply the stoma collection materials before leakages appear.

Figure 23

Figure 24 shows that the results regarding Item seventeen which is "Prevent having leakages" and participants response as only $8(5.3 \%)$ were not confident, $32(21.3 \%)$ were slightly confident, majority $43(28.7 \%)$ were fairly confident, $40(26.7 \%)$ were highly confident and only $27(18 \%)$ were extremely confident.

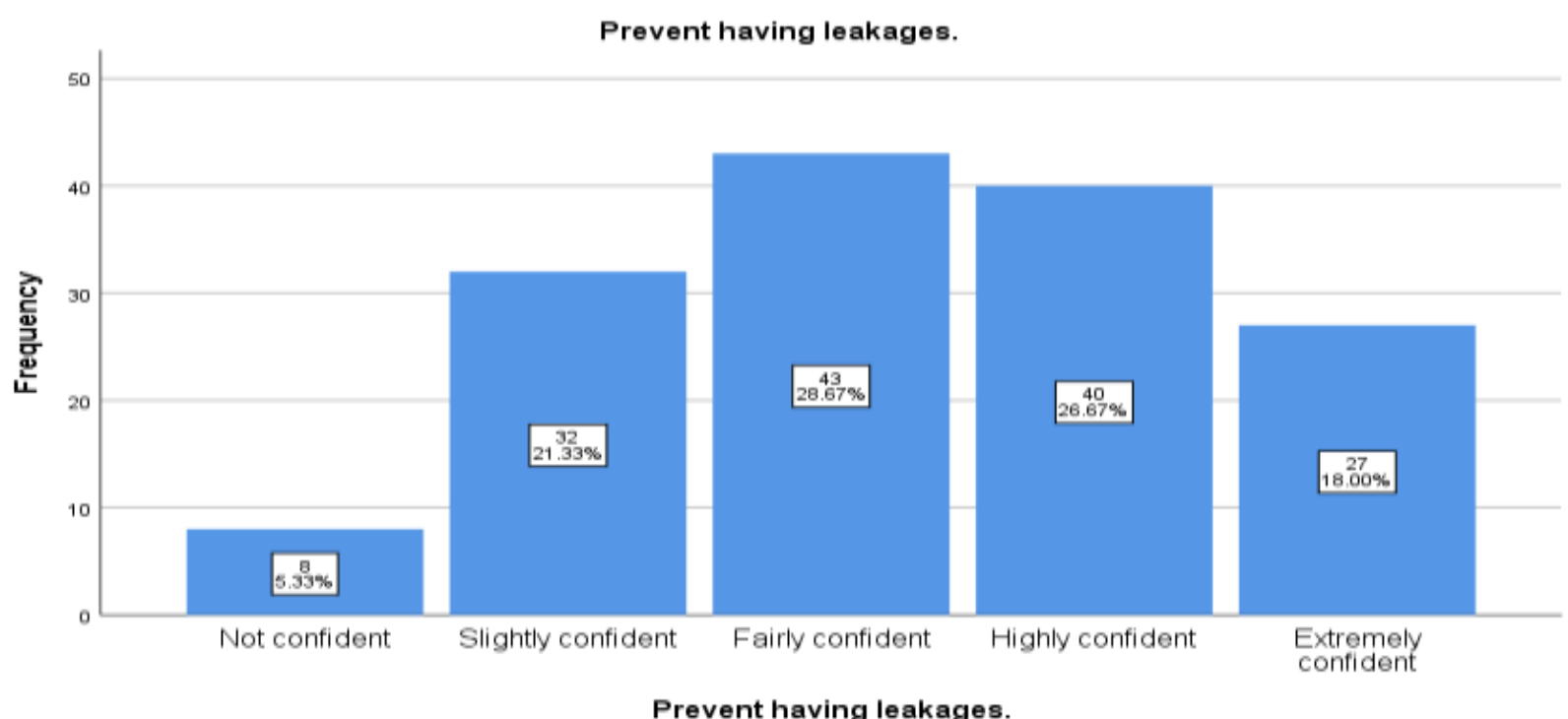

Figure 24

Figure 25 shows that the results regarding item eighteen which is "Take care of the stoma in the right way at home" and participants response as only $1(.7 \%)$ were not confident, $17(11.3 \%)$ were slightly confident, majority 66 (44\%) were fairly confident, 53 (35\%) were highly confident and only 13 (8.7\%) were extremely confident. 


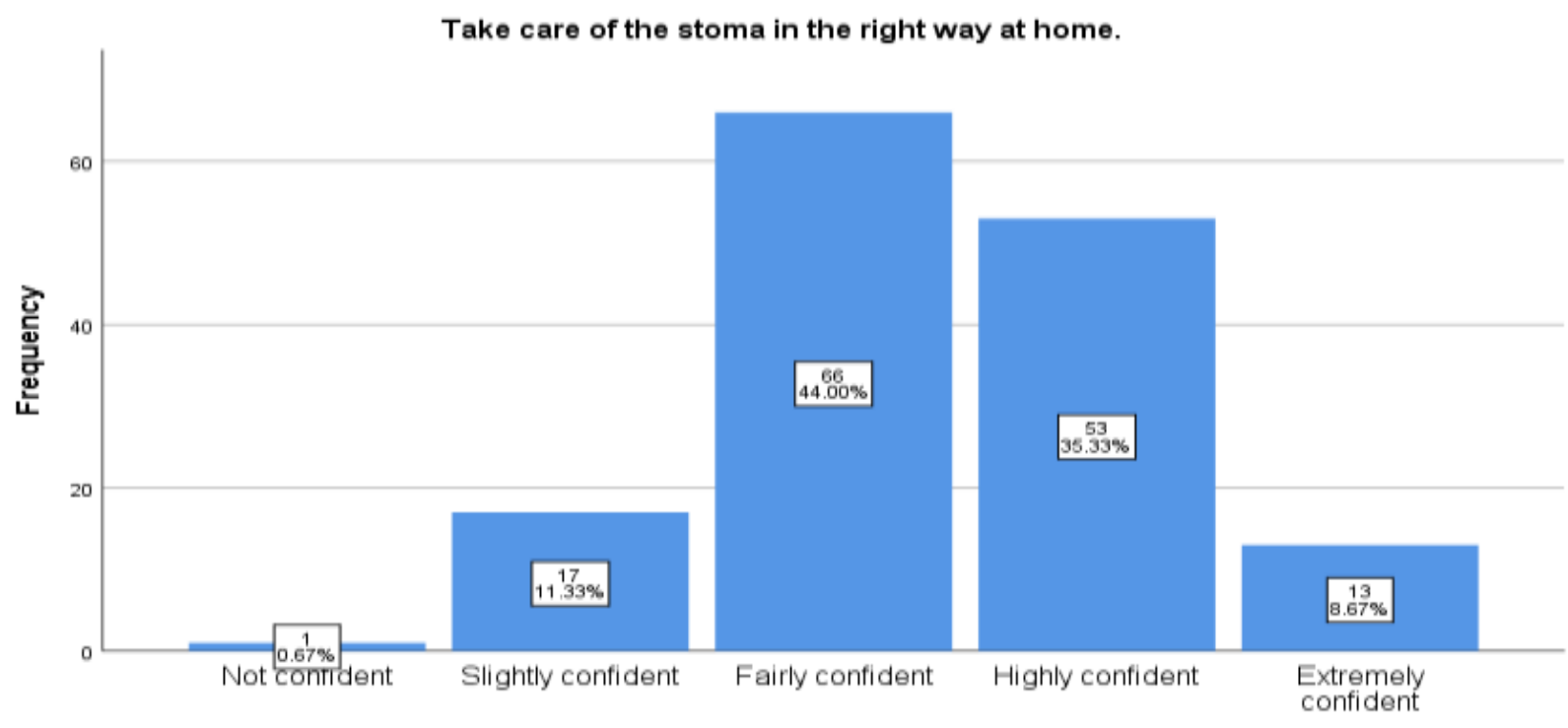

Take care of the stoma in the right way at home.

Figure 25

Figure 26 shows that the results regarding item nineteen which is "Prevent having skin problems." and participants response as only $1(.7 \%)$ were not confident, $48(32 \%)$ were slightly confident, majority $42(28 \%)$ were fairly confident, $44(29.3 \%)$ were highly confident and only 15 (10\%) were extremely confident.

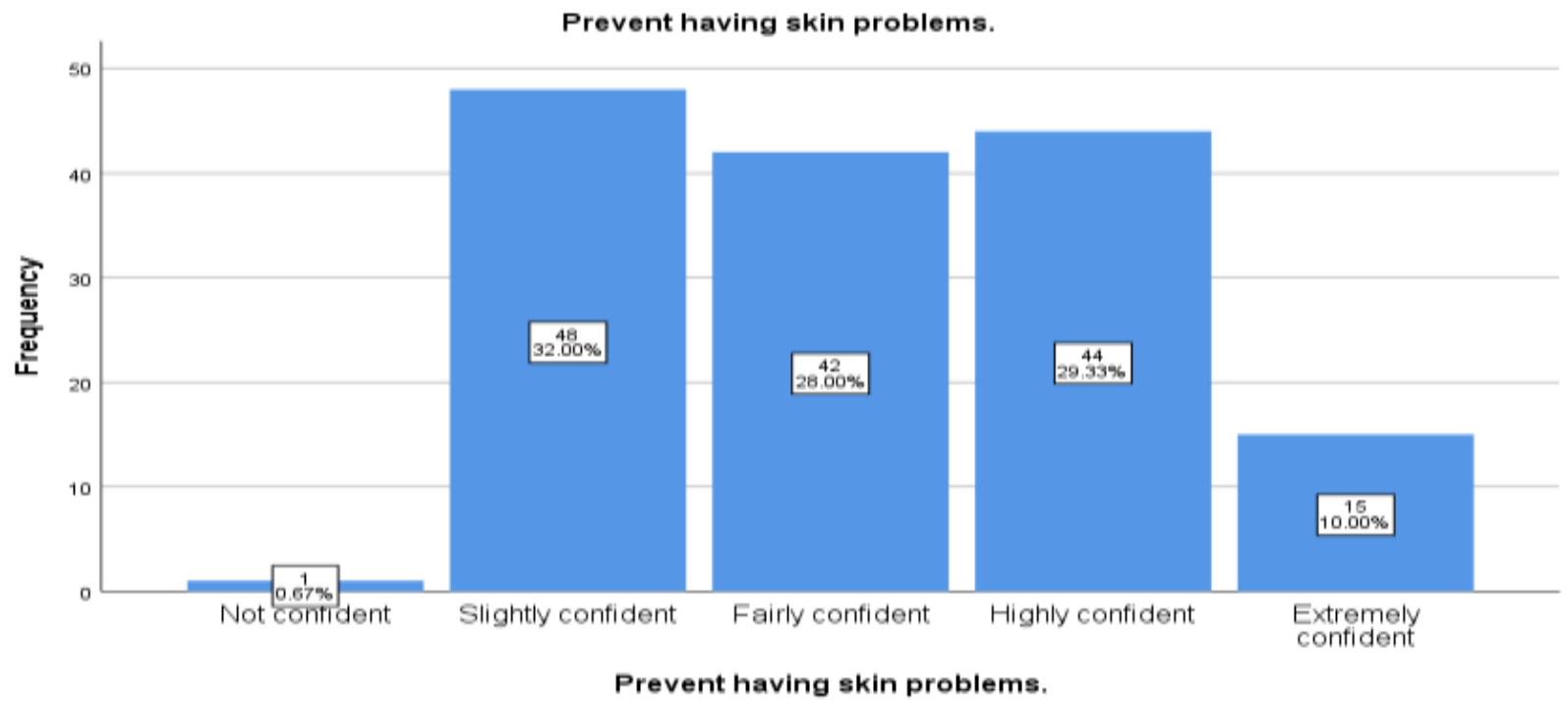

Figure 26

Figure 27 shows that the results regarding item twenty which is "Prevent having stoma bleeding and damage" and participants response as only $30(20 \%)$ were not confident, $47(31.3 \%)$ were slightly confident, majority $36(24 \%)$ were fairly confident, 24 (16\%) were highly confident and only $13(8.7 \%)$ were extremely confident. 


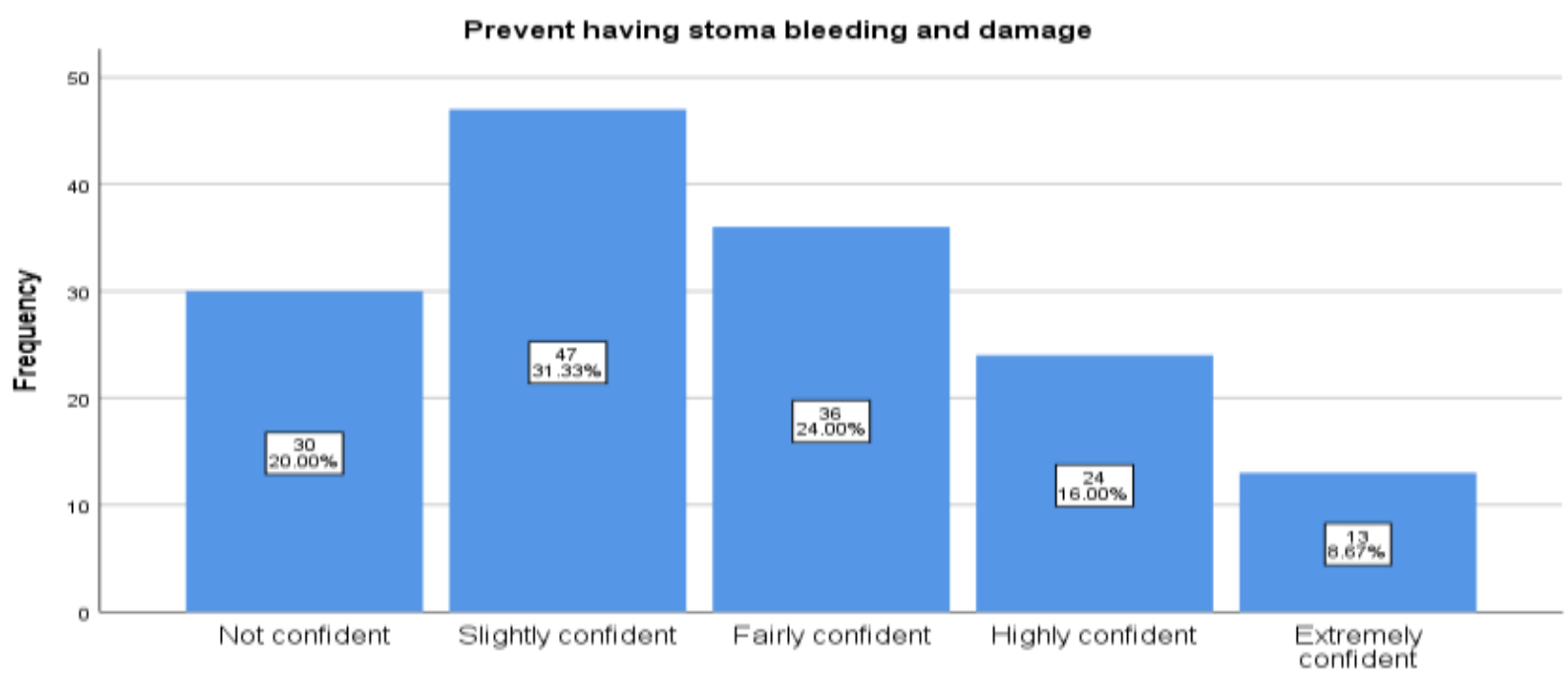

Prevent having stoma bleeding and damage

Figure 27

Figure 28 shows that the results regarding Item twenty-one which is "Apply the stoma collection materials in the way you learned to do." and participants response as only $25(16.7 \%)$ were not confident, 27 (18\%) were slightly confident, majority $42(28 \%)$ were fairly confident, $45(30 \%)$ were highly confident and only $11(7.3 \%)$ were extremely confident.

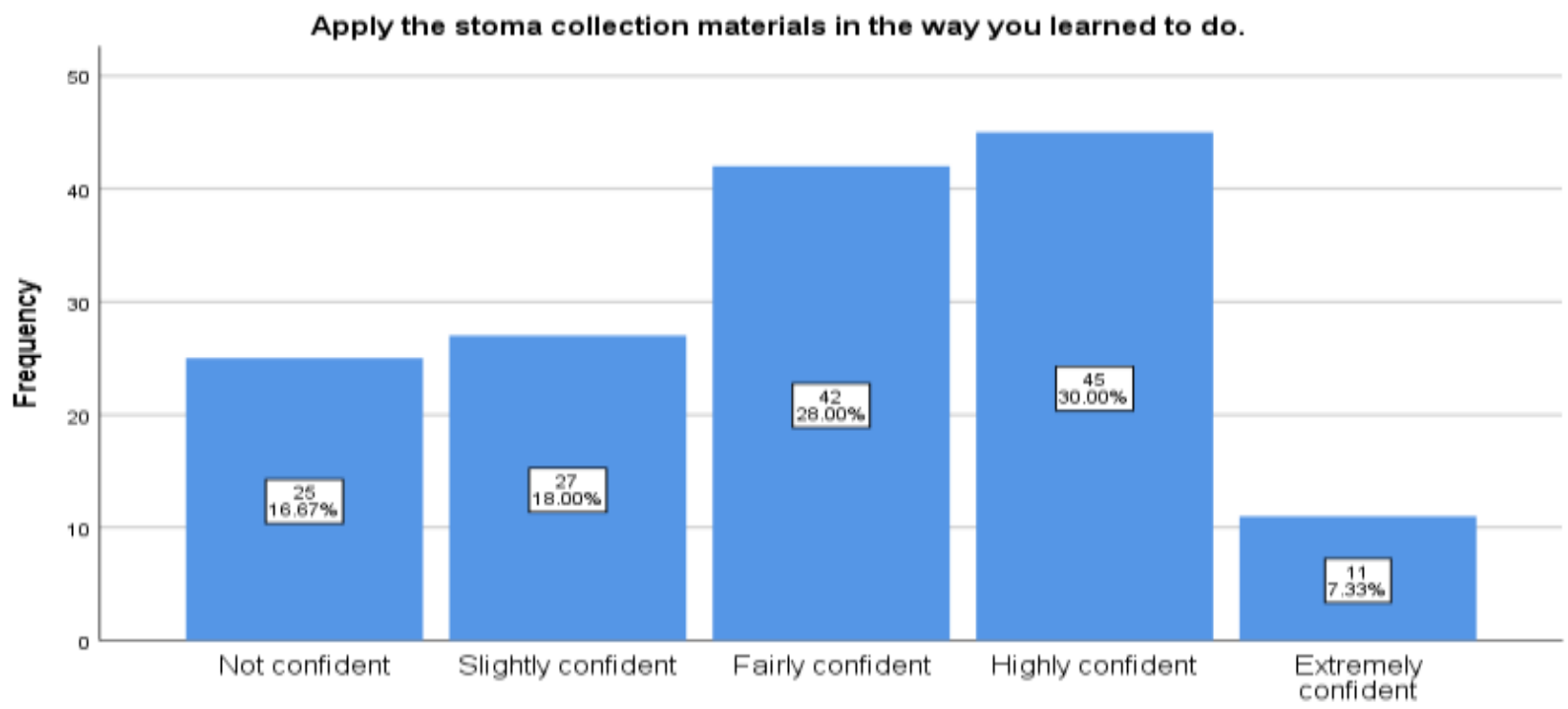

Apply the stoma collection materials in the way you learned to do.

Figure 28

Figure 29 shows that the results regarding item twenty-two which is "Prevent having obstruction" and participants response as only $1(.7 \%)$ were not confident, $33(22 \%)$ were slightly confident, majority $53(35.3 \%)$ were fairly confident, $54(36 \%)$ were highly confident and only $9(6 \%)$ were extremely confident. 


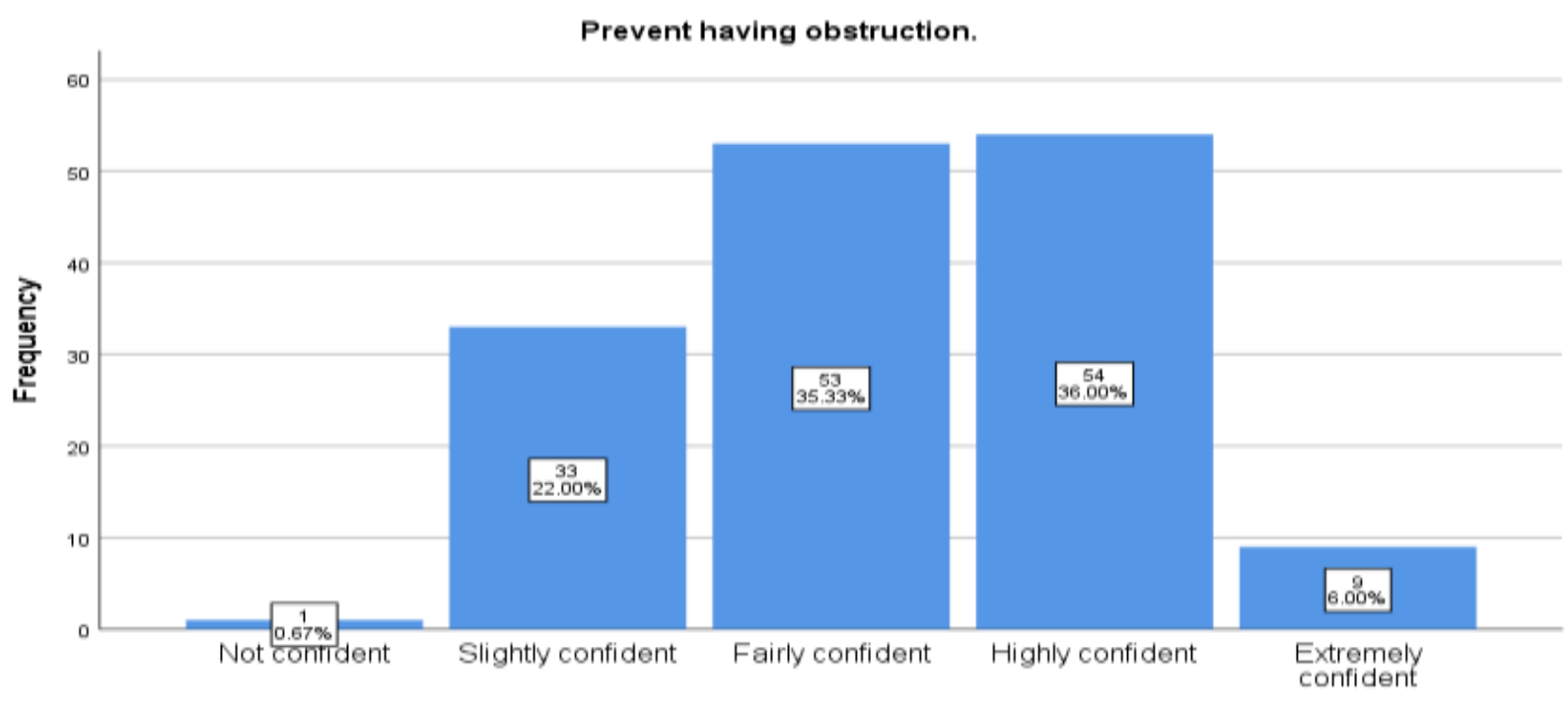

Prevent having obstruction.

Figure 29

Figure 30 shows that the results regarding item twenty-three which is "Follow the nurse's instructions for handling the stoma." and participants response as only $0(0 \%)$ were not confident, $9(6 \%)$ were slightly confident, majority 77 (51.3\%) were fairly confident, 56 (36.7\%) were highly confident and only $9(6 \%)$ were extremely confident.

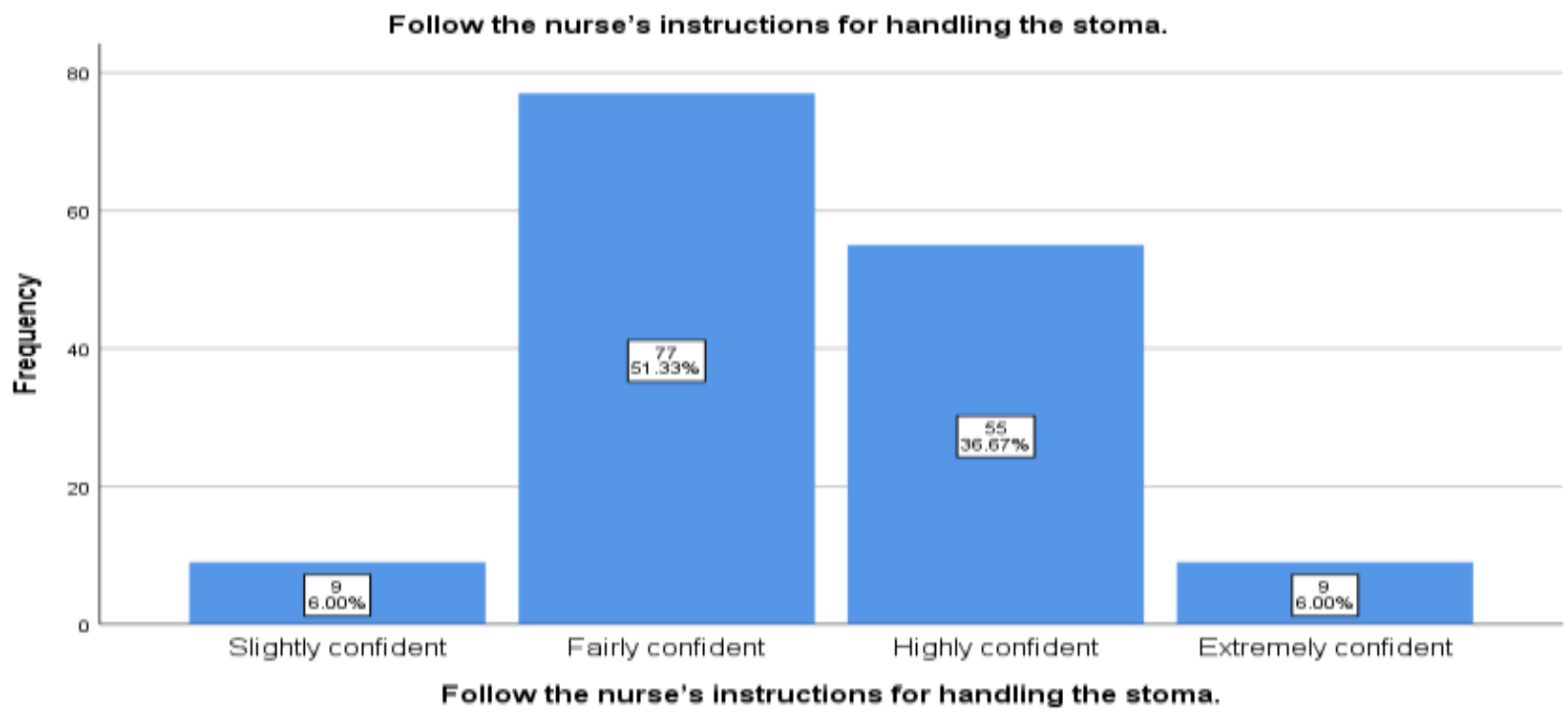

Figure 30

Figure 31 shows that the results regarding item twenty-four which is "Follow the doctor's advice for taking care of your stoma and nutrition pattern" and participants response as only $16(10.7 \%)$ were not confident, $46(30.7 \%)$ were slightly confident, majority $53(35.3 \%)$ were fairly confident, $35(23.3 \%)$ were highly confident and only 0 $(0 \%)$ were extremely confident. 


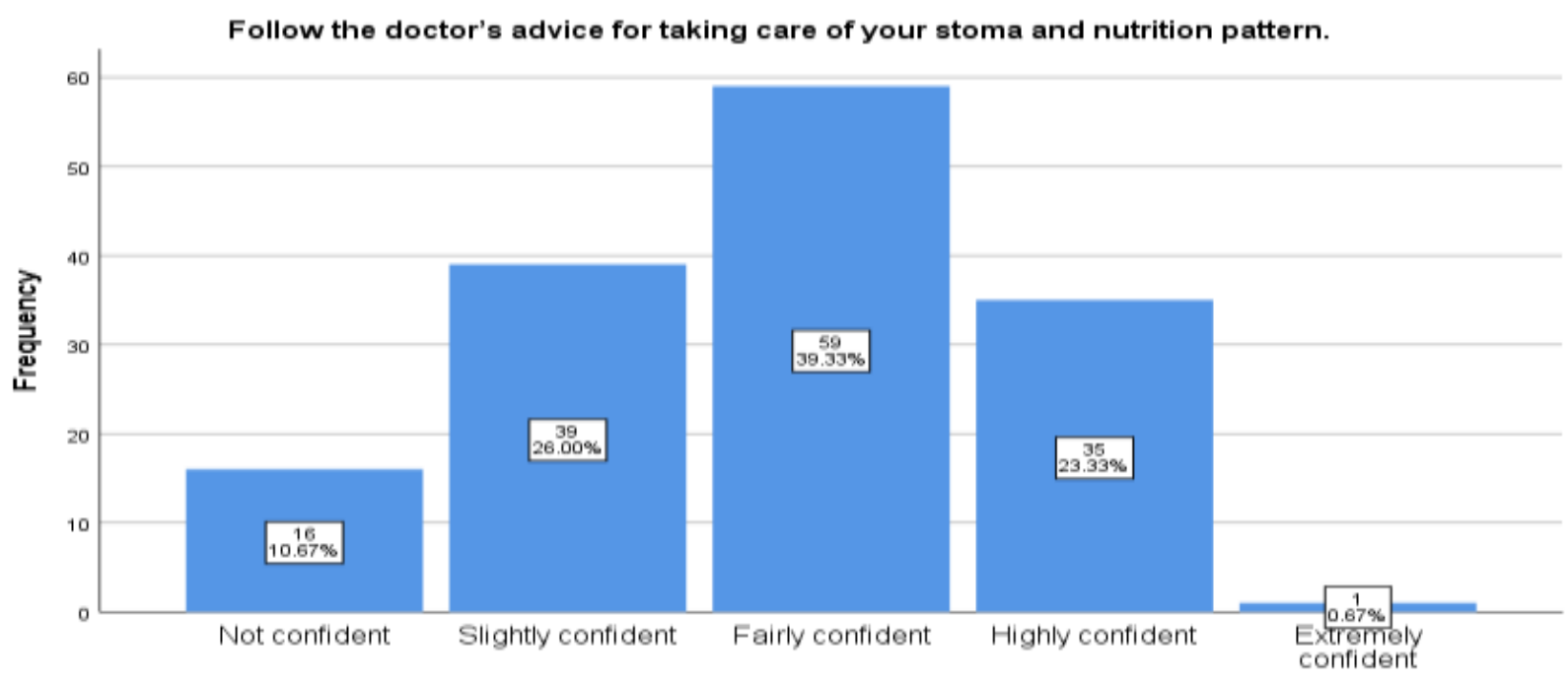

Follow the doctor's advice for taking care of your stoma and nutrition pattern.

Figure 31

Figure 32 shows that the results regarding item twenty-five which is "Take care of the stoma in the right way outdoors" and participants response as only $12(8 \%)$ were not confident, $39(26 \%)$ were slightly confident, majority $41(27.3 \%)$ were fairly confident, $41(27.3 \%)$ were highly confident and only $17(11.3 \%)$ were extremely confident.

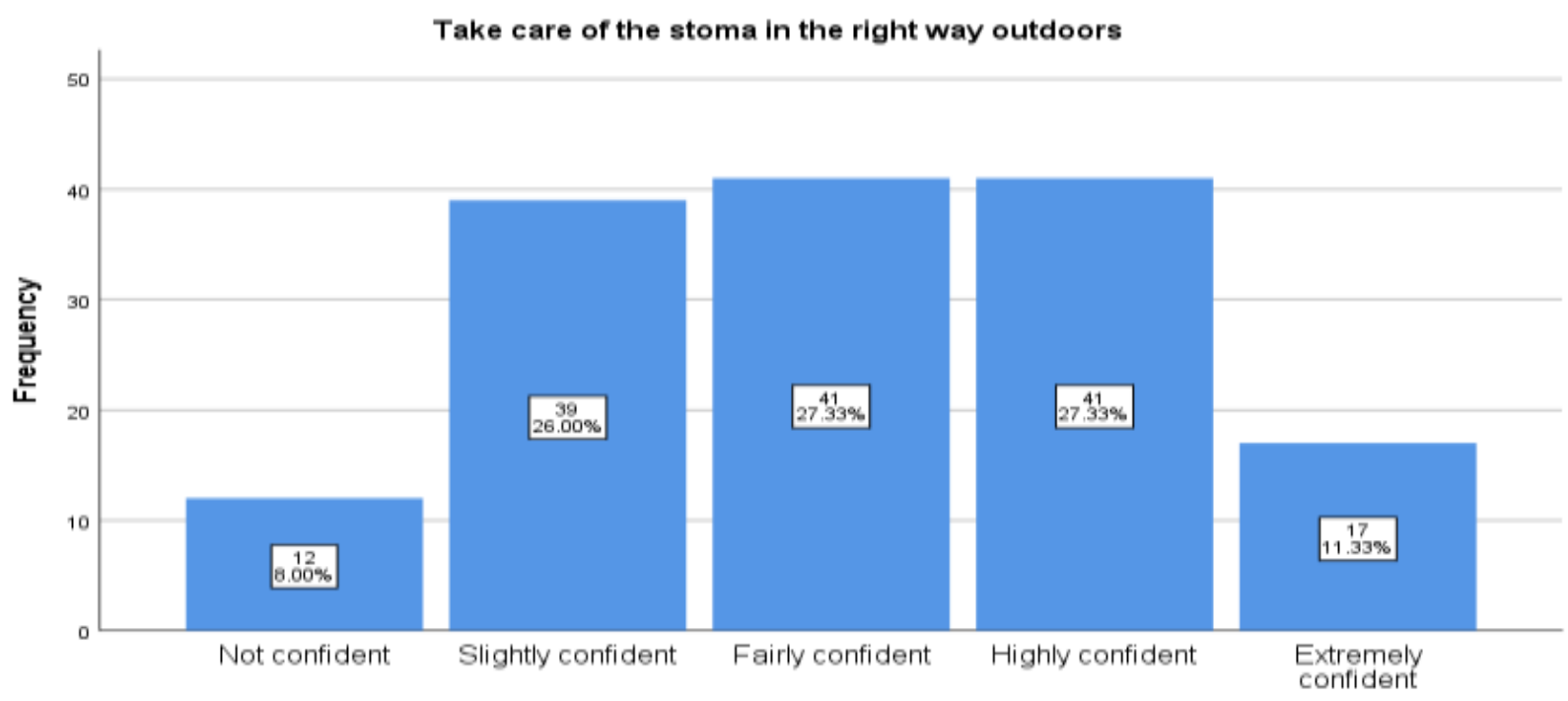

Take care of the stoma in the right way outdoors

Figure 32

Figure 33 shows that the results regarding item twenty-six which is "Take care of the stoma when you are ill." and participants response as only $16(10.7 \%)$ were not confident, $46(30.7 \%)$ were slightly confident, majority 53 $(35.3 \%)$ were fairly confident, $35(23.3 \%)$ were highly confident and only $0(0 \%)$ were extremely confident. 


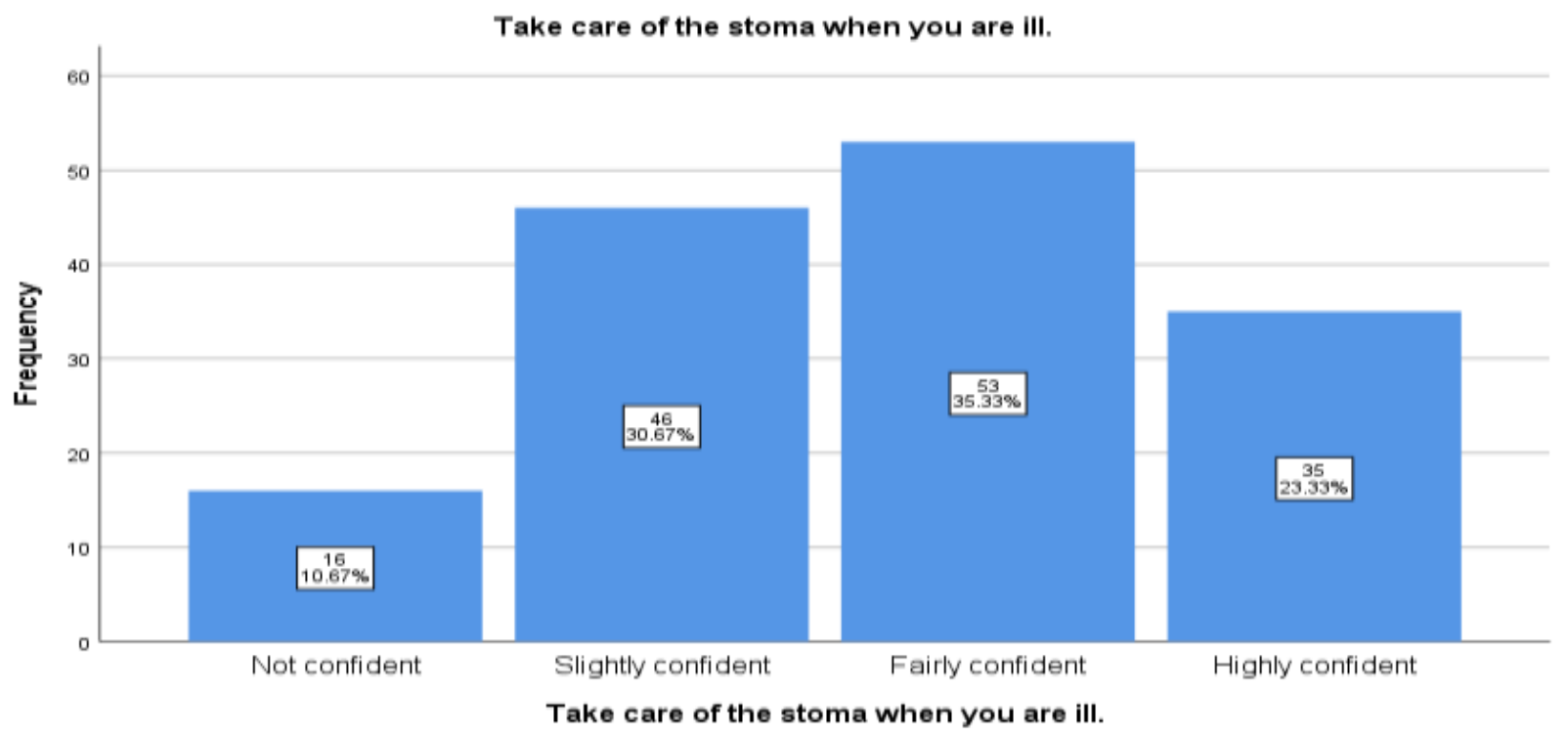

Figure 33

Figure 34 shows that the results regarding item twenty-seven which is "Wear most of the clothes you like" and participants response as only $9(6 \%)$ were not confident, 25 (16.7\%) were slightly confident, majority $47(31.3 \%)$ were fairly confident, $60(40 \%)$ were highly confident and only $9(6 \%)$ were extremely confident.

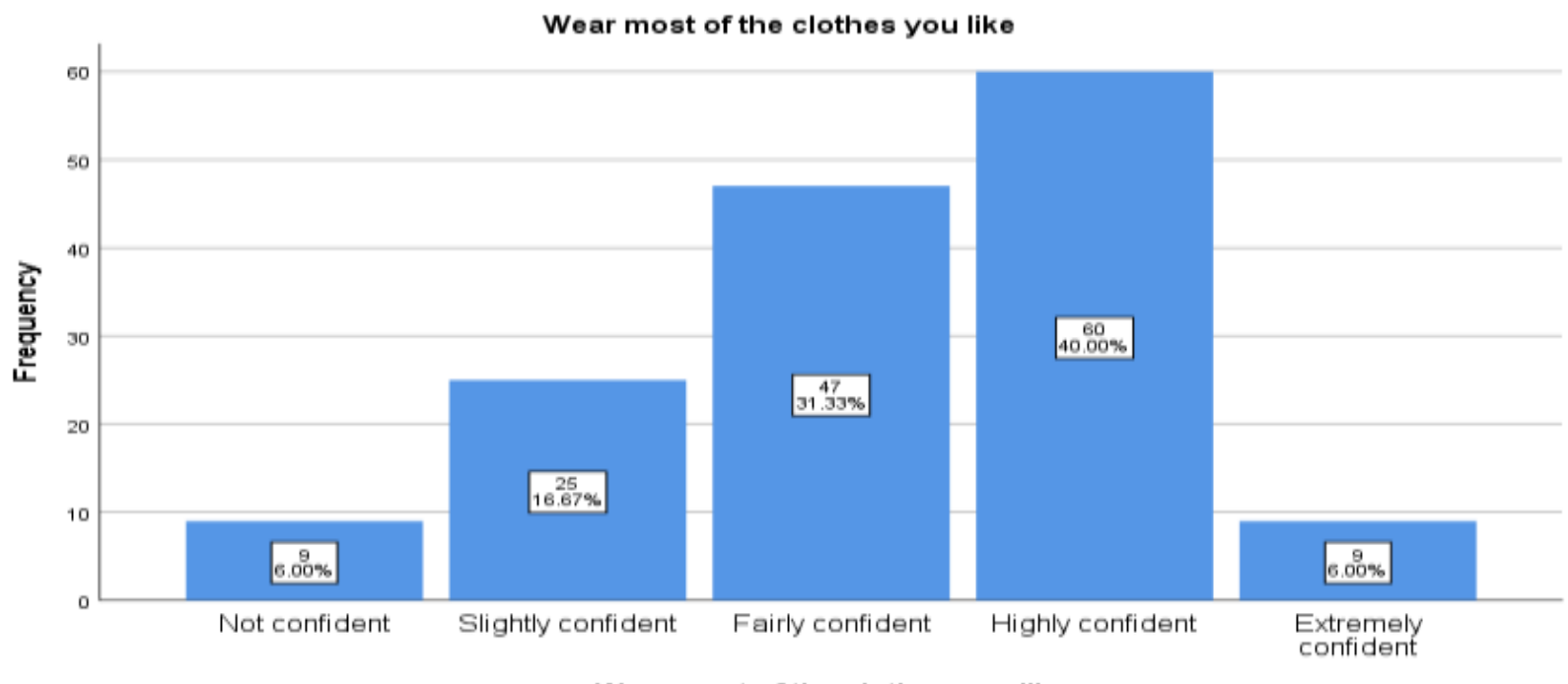

Wear most of the clothes you like

Figure 34

Figure 35 shows that the results regarding item twenty-eight which is "Carry out light duties in and around the house (for instance washing up and gardening)" and participants response as only $12(8 \%)$ were not confident, 28 (18.7\%) were slightly confident, majority $53(35.3 \%)$ were fairly confident, $45(30 \%)$ were highly confident and only $12(8 \%)$ were extremely confident 


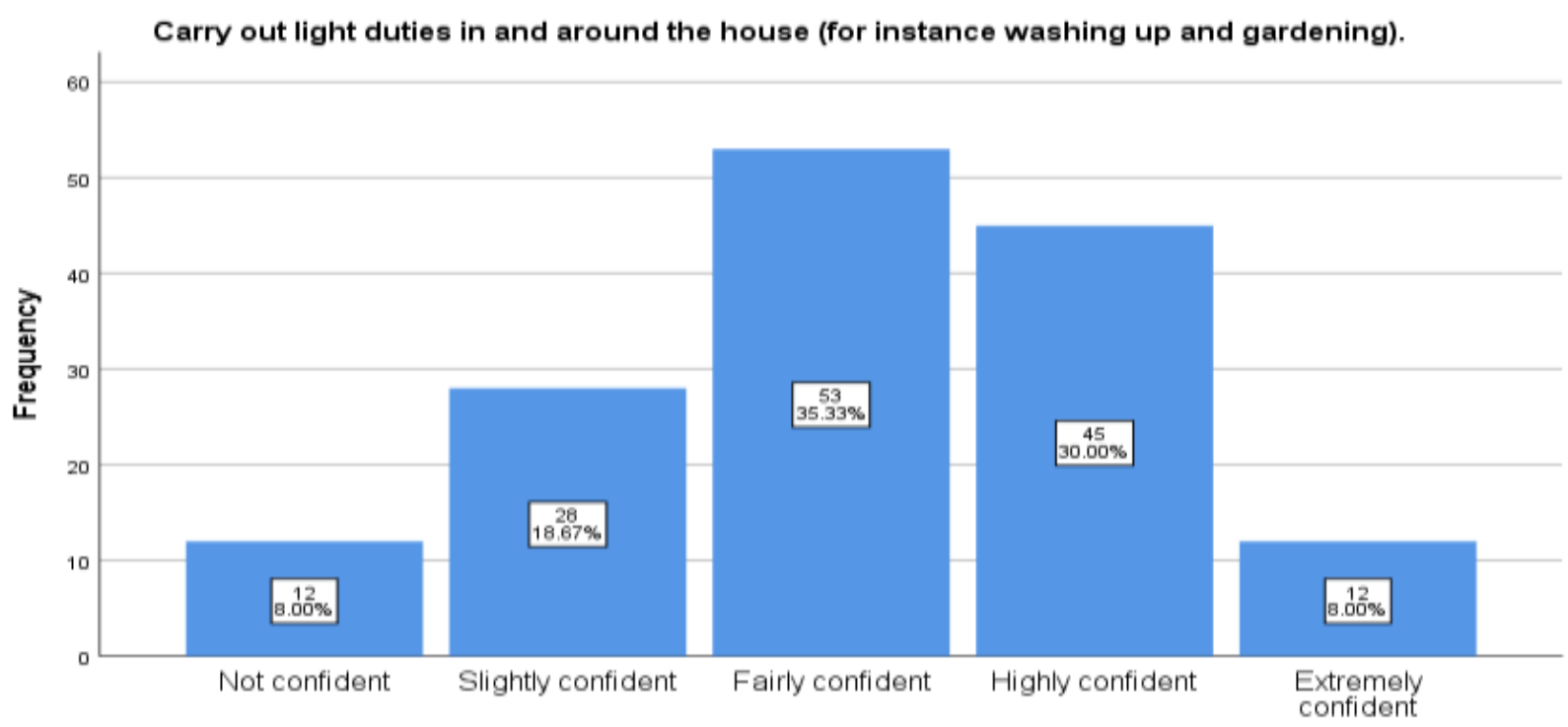

Carry out light duties in and around the house (for instance washing up and gardening).

\section{Figure 35 \\ CHAPTER - V \\ DISCUSSION}

In this study the results revealed that the age of participants was found minimum 21 to highest 60 , participant's age group 21-30 years frequency was 18 (12\%), moderately 48 (32\%) participants were belong to age group 3140 years and $55(36.7 \%)$ were fall in age group $41-50$ years and majority $29(19.3 \%)$ were 51-60-year-old. Which is oppose to the mean age of the respondents was 48.9 years (range 21-80 years) and also similar to the study in Iran in which mean age was 57.49 years (Mahjoubi, Moghimi, Mirzaei, \& Bijari, 2005; Pandey et al., 2015). In this study majority $79(52.7 \%)$ of participants' living with stoma $\leq 12$ months and 71 (47.3\%) living with stoma for $\geq 12$ months. Duration of postoperative hospitalization of the participants was found as $93(62 \%)$ were stayed in hospital for $\leq 15$ days and $57(38 \%)$ were stay for $\geq 15$ day. Assessment regarding Type of stoma and results revealed that majority $68(45.3 \%)$ have found with Ileostomy, $56(37.3 \%)$ have found with Colostomy and 26 (17.3\%) found with Urostomy. 89 (52.7\%) have training and 61 (47.3\%) have not Training on stoma care. 72 (48\%) found as having Pre-operative teaching and majority 78 (52\%) having Pre-operative teaching regarding stoma care. Which is similar to a study conducted in 2015 in cancer hospital their results were majority $(70.2 \%)$ had colostomy. Most of the respondents $(61.7 \%)$ had postoperative hospitalization of $>15$ days. Regarding duration of living with stoma, more than half ostomates (53.2\%) were living with stoma for $>12$ months. Majority of ostomates $(70.2 \%)$ visiting stoma clinic had not received training on stoma care. Preoperative teaching on stoma was provided during stoma site marking and at OPD before consent by concerned doctors. Among the respondent's majority $68.1 \%$ had received preoperative teaching (Pandey et al., 2015). In this study the overall knowledge of respondents regarding item one which was "Black colored stoma is normal" $60(40 \%)$ response as yes, which is correct, 59 (39.3\%) go with no and only $31(20.7 \%)$ response as not know the color of stoma. Item two is 'stoma protruded $>2$ inch is normal" and majority $60(40 \%)$ response correctly as yes, $52(34.7 \%)$ response wrongly as no and $38(25.3 \%)$ were not know the stoma protruded $>2$ inch is normal. The participants response regarding three which is "Continued bleeding from inside stoma for $>10 \mathrm{~min}$ is normal" as majority $88(58.7 \%)$ were go with yes, $54(36 \%)$ response as yes and only $8(5.3 \%)$ did not know about it. These results are near to similar of results on normal stoma and stoma related complication (Mohamed et al., 2017).

Higher self-care efficacy was nearly 50\% Similar study was done among stoma patients in Taiwan using a randomized experimental design. Stoma patients were randomly assigned to multimedia learning education program and a conventional education service program with a follow-up of one week. Knowledge of self-care scale consisting of 22 items related to: anatomy of stoma, types of pouching systems and types of accessories was used and was rated on a dichotomized scale (1, right; 0 , wrong). The pretest means scores in knowledge of Self Care was 7.30 (Lo et al., 2010). Patients with a permanent colostomy wear an appliance to collect feces for the rest of their lives. To return to their previous life activities, patients must acquire knowledge and skills e.g. the ability to perform normal stoma care, identify problems, care for peristomal skin, and understand how to prevent and treat potential complications (Cheng, Meng, Yang, \& Zhang, 2013). This study showed patients have some but not a great deal of knowledge regarding their stoma; the lowest scores were in colostomy irrigation, stoma-related 
complications, and how to measure a stoma. Pakistan has few enterostomal therapists, and most of them work in big urban hospitals. In the authors experience, many patients come from rural areas; they had very little contact with an enterostomal therapists following discharge from the hospital. Thus, patients should be taught about knowledge of stoma caring as early as possible.

Conclusion: In this study, patients with moderately levels of knowledge about stoma care and those who cannot manage all aspects of care independently were not more psychosocially adjusted to their stomas than persons with high knowledge and not more dependence on others for care. The results of this and other studies suggest providing knowledge and emphasizing/teaching self-care before hospital discharge may optimize quality of life for persons with a colostomy.

Recommendations: Results of this study calls for the following recommendations:

- Assessment of patients' self -care performance during first six months after operation considered as evidence to their educational, emotional and psychological needs and concerns.

- Training program for nurses to be well prepared to provide support, instructions and training for colostomy patients.

- Further studies should be carried out on a large number of colostomy patients for evidence of the results and generalization

Acknowledgment: My sincere thanks extend to all patients who participated in the study.

\section{References:}

Arnold, M., Sierra, M. S., Laversanne, M., Soerjomataram, I., Jemal, A., \& Bray, F. (2017). Global patterns and trends in colorectal cancer incidence and mortality. Gut, 66(4), 683-691.

Artino, A. R. (2012). Academic self-efficacy: from educational theory to instructional practice. Perspectives on medical education, 1(2), 76-85.

Bajracharya, S. (2010). The Road of Stoma Care in Nepal. World Council of Enterostomal Therapist, 8-10.

Bulkley, J. E., McMullen, C. K., Grant, M., Wendel, C., Hornbrook, M. C., \& Krouse, R. S. (2018). Ongoing ostomy self-care challenges of long-term rectal cancer survivors. Supportive care in cancer, 26(11), 39333939.

Cheng, F., Meng, A., Yang, L.-F., \& Zhang, Y. (2013). The correlation between ostomy knowledge and self-care ability with psychosocial adjustment in Chinese patients with a permanent colostomy: a descriptive study. Ostomy Wound Manage, 59(7), 35-38.

Cheng, F., Xu, Q., Dai, X.-d., \& Yang, L.-1. (2012). Evaluation of the expert patient program in a Chinese population with permanent colostomy. Cancer nursing, 35(1), E27-E33.

Cheng, F., Xu, Q., Dai, X.-d., \& Yang, L.-1. (2015). Evaluation of the expert patient program in a Chinese population with permanent colostomy. Cancer nursing, 35(1), E27-E33.

Costa, V. F., Alves, S. G., Eufrásio, C., Salomé, G. M., \& Ferreira, L. M. (2014). Assessing the body image and subjective wellbeing of ostomists living in Brazil. Gastrointestinal Nursing, 12(5), 37-47.

Culha, I., Kosgeroglu, N., \& Bolluk, O. (2016). Effectiveness of self-care education on patients with stomas. IOSR Journal of Nursing and Health Science, 5(2), 70-76.

Danielsen, A. K., \& Rosenberg, J. (2014). Health related quality of life may increase when patients with a stoma attend patient education-a case-control study. PLoS One, 9(3).

Dincer, M., \& Çıtlak, G. (2019). Indications and Complications of Stoma Formations in Emergency Surgery. International Journal of Innovative Research in Medical Science, 4(02), 139 to 142-139 to 142.

El Sayed, S. M., Elhameed, S. H. A., \& Hassanen, A. A. Effect of nursing stoma care training on geriatric patients' self esteem and psychological status.

El Sayed, S. M., Elhameed, S. H. A., \& Hassanen, A. A. (2017). Effect of nursing stoma care training on geriatric patients' self esteem and psychological status.

Geleta, T. (2017). Assessment of Knowledge and Associated Factors Regarding Colostomy Care among Staff Nurses Working in Surgical, ICU and Oncology Units at Selected Public Hospitals, Addis Ababa, Ethiopia, 2017. Addis Ababa University.

Golicki, D., Styczen, P., \& Szczepkowski, M. (2013). Quality of life in stoma patients in Poland: multicentre crosssectional study using WHOQOL-BREF questionnaire. Przegl Epidemiol, 67(3), 491-496.

Lim, S. H., Chan, S. W. C., \& He, H.-G. (2015). Patients' experiences of performing self-care of stomas in the initial postoperative period. Cancer nursing, 38(3), 185-193. 
Lo, S. F., Wang, Y. T., Wu, L. Y., Hsu, M. Y., Chang, S. C., \& Hayter, M. (2010). A cost-effectiveness analysis of a multimedia learning education program for stoma patients. Journal of clinical nursing, 19(13-14), 1844-1854.

Mahjoubi, B., Moghimi, A., Mirzaei, R., \& Bijari, A. (2005). Evaluation of the end colostomy complications and the risk factors influencing them in Iranian patients. Colorectal Disease, 7(6), 582-587.

Mohamed, S. S., Salem, G., \& Mohamed, H. A. (2017). Effect of self-care management program on self-efficacy among patients with colostomy. American Journal of Nursing Research, 5(5), 191-199.

Neuman, H. B., Patil, S., Fuzesi, S., Wong, W. D., Weiser, M. R., Guillem, J. G., . . Temple, L. K. (2011). Impact of a temporary stoma on the quality of life of rectal cancer patients undergoing treatment. Annals of surgical oncology, 18(5), 1397-1403.

Nichols, T. R., \& Inglese, G. W. (2018). The burden of peristomal skin complications on an ostomy population as assessed by health utility and the physical component summary of the sf-36v2®. Value in health, 21(1), 89-94.

Pandey, R. A., Baral, S., \& Dhungana, G. (2015). Knowledge and practice of stoma care among ostomates at bp koirala memorial cancer hospital. Journal of Nobel Medical College, 4(1), 36-45.

Pattanaik, S. K. (2018). Emergency management of sigmoid colon volvulus in a volvulus belt population and a review of literature. Indian Journal of Surgery, 80(6), 599-605.

Pontieri-Lewis, V. (2018). Basics of ostomy care. Medsurg Nursing, 15(4), 199.

Pradhananga, K. K., Baral, M., \& Shrestha, B. M. (2014). Multi-institution hospital-based cancer incidence data for Nepal: an initial report. Asian Pac J Cancer Prev, 10(2), 259-262.

Ran, L., Jiang, X., Qian, E., Kong, H., Wang, X., \& Liu, Q. (2016). Quality of life, self-care knowledge access, and self-care needs in patients with colon stomas one month post-surgery in a Chinese Tumor Hospital. International journal of nursing sciences, 3(3), 252-258.

Reese, J. B., Finan, P. H., Haythornthwaite, J., Kadan, M., Regan, K., Herman, J. M., . . . Azad, N. (2014). Gastrointestinal ostomies and sexual outcomes: a comparison of colorectal cancer patients by ostomy status. Supportive care in cancer, 22(2), 461-468.

Richard, A. A., \& Shea, K. (2011). Delineation of self-care and associated concepts. Journal of Nursing Scholarship, 43(3), 255-264.

Scharlach, A., Barrie Robinson, M., Dal Santo, T. S., Guinta, N., \& Kelly Mills-Dick, B. (2014). CARE MANAGEMENT \& QUALITY ASSURANCE UNDER LONG TERM CARE INSURANCE. Berkeley, CA: Center for the Advanced Study of Aging Services.

Shaffy, S., Kaur, S., Das, K., \& Gupta, R. (2012). Physical, nutritional and sexual problems experienced by the patients with colostomy/ileostomy: a qualitative study. Nursing and Midwifery Research Journal, 8(3), 210-222.

SHANMUGAM, D. R. S., \& ANANDHI, M. (2016). Assess the Knowledge, Attitude and Practice on Ostomy Care Among Ostomates Attending Stoma Clinic.

Sheikh, A. A., Joel, A., Johnson, O., \& Vimalachandran, D. (2016). Outcome of colorectal cancer resection in octogenarians. South African Journal of Surgery, 51(2), 68-72.

Stoker, D. E. (2016). An ethnographic examination of life after ostomy surgery: Reconstructing the self: University of Houston.

Tao, H., Songwathana, P., Isaramalai, S. a., \& Wang, Q. (2014). Taking good care of myself: A qualitative study on self-care behavior among $\mathrm{C}$ hinese persons with a permanent colostomy. Nursing \& health sciences, 16(4), 483-489.

Werth, S. L., Schutte, D. L., \& Stommel, M. (2014). Bridging the gap: perceived educational needs in the inpatient to home care setting for the person with a new ostomy. Journal of Wound Ostomy \& Continence Nursing, 41(6), 566-572.

Wilson, F. (2019). History of Ostomy and Urinary Diversions. Urologic Nursing, 39(5).

\section{CLOSTOMY CARE CHECKLIST}

\section{KNOWLEDGE AND PRACTICES OF STOMA CARE AMONG PATIENTS}

This study is done by Ms. Neelam in the supervision of respected preceptor, department Nursing. The purpose of this study is to investigate the "knowledge and practices of stoma care among patient". Your participation is completely voluntary. You may withdraw at any time for any reason without explanation and without penalty. All records of participation will be kept strictly confidential, such that only I and my supervisor will have access to the information. Your participation in this study will be highly appreciated. 
Section A: Demographics

Respond by circling (O) or ticking () the most appropriate responses

\begin{tabular}{|c|c|c|c|}
\hline Gender & $\begin{array}{l}\square \text { Male } \\
\square \text { Female }\end{array}$ & $\begin{array}{l}\text { Duration of } \\
\text { postoperative } \\
\text { hospitalization }\end{array}$ & $\begin{array}{l}\boldsymbol{\square} \leq 15 \text { days } \\
\mathbf{\square} \geq 15 \text { day }\end{array}$ \\
\hline Education level & $\begin{array}{l}\text { Illiterate } \\
\square \text { Primary (class 1-8) } \\
\square \text { Lower secondary (class 9-10) } \\
\square \text { Higher secondary (class 11-12) } \\
\square \text { Higher education (above 12) }\end{array}$ & Type of stoma & $\begin{array}{l}\boldsymbol{\square} \text { Colostomy } \\
\boldsymbol{\square} \text { Ileostomy } \\
\boldsymbol{\square} \text { Urostomy }\end{array}$ \\
\hline $\begin{array}{l}\text { Duration of } \\
\text { living with stoma }\end{array}$ & $\begin{array}{l}\boldsymbol{\square} \leq 12 \text { months } \\
\boldsymbol{\square} \geq 12 \text { months }\end{array}$ & $\begin{array}{l}\text { Training on } \\
\text { stoma care }\end{array}$ & $\begin{array}{l}\square \text { Yes } \\
\square \text { No }\end{array}$ \\
\hline Age & $\begin{array}{l}\square 21-30 \text { years } \\
\square 31-40 \text { years } \\
\square \text { 41-50 years } \\
\square 51-60 \text { years }\end{array}$ & $\begin{array}{l}\text { Pre-operative } \\
\text { teaching }\end{array}$ & $\begin{array}{l}\square \text { Yes } \\
\square \text { No }\end{array}$ \\
\hline
\end{tabular}

Section B: Knowledge regarding Complication of Stoma

\begin{tabular}{|c|c|c|c|c|}
\hline SN & Items & Yes & No & Not know \\
\hline 1 & Black colored stoma is normal & & & \\
\hline 2 & Stoma protruded $>2$ inch is normal & & & \\
\hline 3 & Continued bleeding from inside stoma for $>10 \mathrm{~min}$ is normal & & & \\
\hline
\end{tabular}

Knowledge regarding Normal Stoma

\begin{tabular}{|c|l|c|c|c|c|}
\hline SN & Items & $\mathbf{1}$ & $\mathbf{2}$ & $\mathbf{3}$ & $\mathbf{4}$ \\
\hline $\mathbf{4}$ & Color of normal stoma & Red & Pale & Black & Don't know \\
\hline $\mathbf{5}$ & Appearance of normal stoma & $\begin{array}{c}\text { Shiny and } \\
\text { moist }\end{array}$ & Has nodules & $\begin{array}{c}\text { Has cuts and } \\
\text { torn }\end{array}$ & Don't know \\
\hline $\mathbf{6}$ & Normal peristomal skin condition & $\begin{array}{c}\text { Similar to } \\
\text { other skin }\end{array}$ & Red & $\begin{array}{c}\text { Painful to } \\
\text { touch }\end{array}$ & Don't know \\
\hline
\end{tabular}

Section C: Daily care practices

1. Handwashing before procedure?
A. Yes
B. No

2. Handwashing after procedure?
A. Yes
B. No

3. Practice of emptying stoma pouch?
A. Totally filled
B. Half filled
C. $1 / 3$ rd filled
D. $<1 / 3$ rd filled

4. Technique of cleaning stoma?
A. Periphery to center
B. Centre to periphery

Practices regarding Physical Problem and management

5. Deal physical problem related to stoma
A. Yes
B. No

6. Present physical problems 

A. Leakage
B. Peristomal
C. Skin irritation
D. Odor

7. Practice regarding physical problem
A. Solving peristomal skin irritation
B. Use of stoma powder
C. Attend stoma clinic
D. Clean stoma and change pouch if liquid seeps under barrier

8. Practice regarding solving leakage
A. Reducing size of aperture of flange of pouch
B. Use 2-piece pouch
C. Check adhesive pad for proper seal
D. Others

9. Practice regarding solving odor
A. Change diet
B. Increased fluid intake
C. Use deodorant
D. Others

\section{Section D: Self Care Efficacy}

Not confident $=1$, Slightly confident $=2$, Fairly confident $=3$, Highly confident $=4$, Extremely confident $=5$

\begin{tabular}{|c|c|c|c|c|c|c|}
\hline SN & Items & 1 & 2 & 3 & 4 & 5 \\
\hline 1 & Apply the stoma collection materials before leakages appear. & & & & & \\
\hline 2 & Prevent having leakages. & & & & & \\
\hline 3 & Take care of the stoma in the right way at home. & & & & & \\
\hline 4 & Prevent having skin problems. & & & & & \\
\hline 5 & Prevent having stoma bleeding and damage & & & & & \\
\hline 6 & Apply the stoma collection materials in the way you learned to do. & & & & & \\
\hline 7 & Prevent having obstruction. & & & & & \\
\hline 8 & Follow the nurse's instructions for handling the stoma. & & & & & \\
\hline 9 & Follow the doctor's advice for taking care of your stoma and nutrition pattern. & & & & & \\
\hline 10 & Take care of the stoma in the right way outdoors & & & & & \\
\hline 11 & Take care of the stoma when you are ill. & & & & & \\
\hline 12 & Wear most of the clothes you like & & & & & \\
\hline 13 & $\begin{array}{l}\text { Carry out light duties in and around the house (for instance washing up and } \\
\text { gardening). }\end{array}$ & & & & & \\
\hline
\end{tabular}

